\title{
Carpus and tarsus of Temnospondyli
}

\section{David Dilkes}

Department of Biology \& Microbiology, University of Wisconsin Oshkosh, 800 Algoma Blvd., Oshkosh, WI 54901-8640; e-mail: dilkes@uwosh.edu

Abstract: The carpus of Eryops megacephalus and tarsus of Acheloma cumminsi known from complete and articulated individuals have provided the standard anatomy of these skeletal regions for temnospondyls. Restudy of the carpus of Eryops confirms the presence of only four digits, but refutes evidence for a prepollex, postminimus, and distal carpal 5. The supposed contact surface on centrale 1 for a prepollex is reinterpreted as part of the articulation for metacarpal 1 that includes distal carpal 1. Contrary to previous interpretations, a notch on the intermedium does not fit against the lateral corner of the radius. An articular surface on the distal end of the ulna thought previously to contact an absent postminimus fits against the ulnare. Preparation of the tarsus of the type specimen of Trematops milleri (junior synonym of Acheloma cumminsi) and a previously undescribed crus and pes of Eryops finds no evidence for a pretarsale in either genus. Centrale 4 of the tarsus shares a similar rectangular shape with a wide contact for the tibiale among several temnospondyls whether terrestrial or aquatic. Limited flexibility of the carpus of Eryops and a strong palmar arch are probably weight-bearing features. A proximal-distal line of flexibility is present along the tibial side of the tarsus between the tibiale and centrale 4 and between centrale 2 and centrale 1. A phylogenetic analysis of Temnospondyli including new characters of the carpus and tarsus reveals considerable instability, highlighting the significance of Dendrerpeton acadianum, Balanerpeton woodi, Capetus palustris, and Iberospondylus schultzei.

Key Words: temnospondyl, carpus, tarsus, phylogeny, Eryops, Acheloma, functional morphology, Permian

\section{INTRODUCTION}

The autopodium consisting of the carpus (wrist) or tarsus (ankle) and the digits is the hallmark feature of the tetrapod limb. Bones of the carpus and tarsus articulate with each other, proximally with bones of the zeugopodium (radius and ulna/ tibia and fibula), and distally with the digits. In this location between the digits and zeugopodium, the carpus and tarsus in a quadruped often provide flexibility for flexion and extension and support of the body during locomotion. The evolutionary origin of the carpus and tarsus is not coincident with the origin of digits despite the evidence for homology between digits and distal radials in the extinct sarcopterygian fish Panderichthys (Boisvert et al. 2008), extant lungfish (Johanson et al. 2007), and conserved activity of enhancers of Hox genes for development of fins in fish and limbs in tetrapods (Gehrke et al. 2015). Proximal elements of the wrist (ulnare and intermedium) and ankle (fibulare and intermedium) are present in the more fish-like tetrapodomorphs (Andrews and Westoll 1970; Boisvert et al. 2008; Davis et al. 2004; Shubin et al. 2006) predating the appearance of tetrapod digits. A single element in the tarsus of Tiktaalik is a possible intermedium

\section{Published 22 October 2015}

(c) 2015 by the author

submitted July 10, 2015; revisions received Oct. 5, 2015;

accepted Oct. 5, 2015. Handling editor: Alison Murray.
(Shubin et al. 2014). Only a single ossified bone identified as the intermedium is known for the carpus of the stem tetrapod Acanthostega (Coates 1996), but a second stem tetrapod Tulerpeton has an ossified ulnare and intermedium (Lebedev and Coates 1995). The carpus of Tulerpeton includes the radiale, another standard proximal carpal bone. The manus is largely unknown for Ichthyostega although one specimen has some apparent metacarpals (Callier et al. 2009). Acanthostega, Ichthyostega, and Tulerpeton have a fibulare, intermedium and a third proximal tarsal bone the tibiale (Coates 1996; Lebedev and Coates 1995). The more distal carpal and tarsal bones next to the metacarpals and metatarsals, respectively, are also present in early tetrapods. However, there is far more variability in the number of central bones typically known as the centralia, and their evolution evidently lagged behind that of the remainder of the carpus and the digits (Johanson et al. 2007). Subsequent evolution of the carpus and tarsus involved addition of centralia to a stable number of four.

The presumably more structurally stabilized carpus and tarsus are unknown in many extinct post-Devonian tetrapods, either because these regions were not recovered or identified in fossils, or were cartilaginous at the time of death. Even if present, carpals and tarsals may be small, poorly ossified shapeless bones. The cartilaginous or incompletely ossified 
state of the carpus and tarsus is a consequence of delayed ossification. There is a proximal-distal sequence of ossification in the limbs, and the carpals and tarsals are some of the last regions to ossify, if they ossify at all (Fröbisch et al. 2010). The tarsus sometimes ossified before the carpus. Greererpeton burkemorani has a well-ossified tarsus in which individual bones can be recognized (Godfrey 1989) but the carpus, although ossified, is disarticulated and the unusual shapes of the elements severely limits meaningful comparisons with carpi of other tetrapods. Tarsals are present, but unidentified, in the stem-tetrapod Eucritta melanolimnetes, and there are no ossified carpals (Clack 2001). Fossils of the amphibamid Eoscopus have a complete tarsus that can be compared to the tarsus of Acheloma, but the carpus is incomplete, and many bones cannot be identified with certainty (Daly 1994). A well-ossified tarsus consisting of the fibulare, intermedium, tibiale, four centralia, and the first distal tarsal is known for the stem-amniote Proterogyrinus scheelei, but only two distal carpals are ossified (Holmes 1984). The fibulare, intermedium, tibiale, and two centralia are known for the tarsus of Archeria, but of the carpus, only the radiale is known (Romer 1957). Five tarsals including an intermedium and fibulare, but no carpals, are described for the stem-amniote Silvanrepeton miripedes (Ruta and Clack 2006). Specimens of Gephyrostegus bohemicus have a pair of carpals (possibly the radiale and intermedium) and a modified tarsus consisting of a partially fused tibiale and intermedium, fibulare, three centralia, and five distal tarsals (Carroll 1970; Rieppel 1993). Several tarsals are also known for Westlothiana lizziae (Smithson et al. 1994). Only a single tarsal, probably a fibulare, is known for the stem tetrapod Ossinodus pueri from the Early Carboniferous of Australia (Warren and Turner 2004). These examples demonstrate that while a wide diversity of early tetrapods have preserved carpal and tarsal elements, the tarsus is invariably better represented, and their precise morphologies and homologies are often uncertain.

The best-known and indeed archetypical carpal and tarsal anatomies for early tetrapods are exhibited in the carpus of Eryops megacephalus and the tarsus of Acheloma cumminsi. Eryops has been the subject of numerous publications over the past hundred and fifty years covering aspects such as cranial anatomy (Sawin 1941), vertebrae and ribs (Moulton 1974), and the limbs and girdles (Gregory et al. 1923; Miner 1925; Pawley and Warren 2006). Of particular significance is a specimen of the forelimb of Eryops with a complete carpus described and best illustrated by Gregory et al. (1923) and Miner (1925). This single specimen (AMNH FARB 4186) consisting of an ulnare, intermedium, radiale, four centralia, and four distal carpals, established the general morphology of the carpus for temnospondyls. Similarly, a single complete specimen of the tarsus of the trematopid Trematops milleri, now recog- nized as a junior synonym of Acheloma cumminsi (Dilkes and Reisz 1987), laid the foundation for our understanding of the temnospondyl ankle (Schaeffer 1941) which became the generalized non-amniote tarsal pattern and the starting point for the origin of the amniote tarsus (Meyer and Anderson 2013; O'Keefe et al. 2006; Peabody 1951). Description of this specimen showed the temnospondyl tarsus to consist of a tibiale, intermedium, fibulare, four centralia, and five distal tarsals (Schaeffer 1941).

The carpus and tarsus have provided little data for phylogenies of temnospondyls and other early tetrapods because they typically do not preserve or only a few poorly ossified elements are present. In order to address this issue, the following material will be reexamined: 1 , the carpus of Eryops derived from the specimen described in Gregory et al. (1923); 2, the tarsus of Acheloma from the specimen described by Schaeffer (1941); and 3, the carpal and tarsal bones of Dissorophus multicinctus described briefly in DeMar (1968). For the first time, the tarsus in the holotype of Trematops milleri, and isolated carpal and tarsal bones of Cacops aspidephorus will be described. New phylogenetic characters of the carpus and tarsus will be included in a phylogenetic analysis of Temnospondyli using the data matrix of Schoch (2013). The node based definition of Temnospondyli given by Schoch (2013) as the least inclusive clade of Edops and Mastodonsaurus will be followed.

\section{MATERIALS}

Directional Terms: Locations of articular facets on individual bones and sides of articulated limbs will be described using standard directional terms. Dorsal (extensor) refers to the front (upper) side of the manus and pes facing the vertebral column. Ventral (flexor) is the side facing the ground and refers to the palmar (manus) or plantar (pes) side. Proximal is closer to the attachment of the limb to the body and distal further away from this attachment. Medial (preaxial) and lateral (postaxial) refer to the sides with the first and last digit, respectively.

Ossification of Carpals and Tarsals: Bones compared for any taxonomic, phylogenetic, or biomechanical interpretations should be at similar degrees of ossification. The typically unossified or marginally ossified carpus and tarsus of stereospondyls (Schoch and Milner 2000) likely correlated with a predominantly aquatic lifestyle severely restricting comparisons with other tetrapods. Larger and presumably fully mature individuals perhaps capable of some terrestrial locomotion have a variable number of ossified carpals and tarsals (Boy 1988; Schoch and Witzmann 2009; Witzmann and Schoch 2006). These individuals offer the best chance for meaningful comparisons assuming the preserved bones reflect accurate relative size differences and accurate shapes. 
Specimens Examined: AMNH FARB 4186, articulated left forelimb of Eryops megacephalus consisting of the humerus, radius, ulna, carpus, and partial digits; FMNH UC 930, isolated carpal and tarsal elements of Cacops aspidephorus; FMNH UC 640, holotype of Trematops milleri consisting of an incomplete skull, vertebral column, and appendicular skeleton; FMNH UC 1756, incomplete skeleton of Acheloma cumminsi; MCZ 7555, right tibia, distal half of right fibula, most bones of the tarsus, portions of the first four metatarsals, and several phalanges; MCZ 4169, left hind limb of Dissorophus multicinctus; MCZ 4172 and 4173, incomplete skeletons of Dissorophus multicinctus with partial forelimbs.

Locality Data: All specimens described in this paper were collected from the lower Permian of Texas. There is scant locality data for the AMNH FARB 4186. Records at the American Museum of Natural History show Jacob Boll and his assistant J.C. Isaac collected this specimen in February of 1878 in Wichita County, Texas. These men collected south of the Wichita River in Wichita County during the winter of 1877-1878 (Craddock and Hook 1989) placing the undetermined locality most likely in the Petrolia Formation of the Wichita Group (Hentz 1988). The articulated crus and pes of Eryops MCZ 7555 was collected in 1953 three miles south of Black Flat, Archer County in the Nocona Formation (Wichita Group). Specimens of Dissorophus multicinctus (MCZ 4169, 4172, 4173) were collected from the Arroyo Formation along Indian Creek in Baylor County, equivalent to the base of the undivided Clear Fork Group (Hentz 1988). Similarly, specimen FMNH UC 640 of Acheloma cumminsi was collected from the Arroyo Formation, Craddock bone bed locality at the Craddock Ranch near Brush Creek, Baylor County (Romer 1928; Williston 1909) and FMNH UC 1756 was collected from the Arroyo Formation, East Coffee Creek locality, Baylor County (Olson 1941; Romer 1928). Individual carpal and tarsal bones of Cacops aspidesphorus (FMNH UC 930) were collected from the Cacops bone bed at the base of the Clear Fork Group, Baylor County (Williston 1911).

Anatomical Abbreviations: cen. 1-4, centralia 1 to 4; dc. 1-4, distal carpals 1 to 4; delt, deltoid crest; dt. 1-5, distal tarsals 1 to 5; ect, ectepicondyle; ent, entepicondyle; f, fibula; f. cen. 2 , facet for centrale 2; f. cen. 3 , facet for centrale 3; f. dc. 4, facet for distal carpal 4; f. int, facet for intermedium; f. $r$, facet for radius; $f$. rad, facet for radiale; $f$. tib, facet for tibiale; f. uln, facet for ulnare; fem, femur; fib, fibulare; gr, groove; hum, humerus; int, intermedium; mc. 1-4, metacarpals 1 to 4 ; mt. 1-5, metatarsals 1 to 5 ; r, radius; rad, radiale; rc, radial condyle; sup, supinator process; t, tibia; tib, tibiale; $u$, ulna; uln, ulnare; ung, ungual.
Institutional Abbreviations: AMNH FARB, American Museum of Natural History, New York, U.S.A; FMNH UC, Field Museum of Natural History, Chicago, U.S.A.; MCZ, Museum of Comparative Zoology, Cambridge, U.S.A.

\section{DESCRIPTION}

\section{Carpus}

Ulnare: The ulnare of Eryops is a proximo-distally elongate bone contacting medially the ulna and the intermedium and distally distal carpal 4 (Figs. 1, 2). Its flattened proximal end projects laterally away from the carpus. A single slightly deformed right ulnare in a specimen of Dissorophus multicinctus (Figs. 2C, D, 3) has a similar shape as the ulnare of Eryops and similarly placed articular surfaces for the ulna, intermedium, and distal carpal 4. There is a slight rim along the dorsal edge of the contact surface between the ulnare and intermedium in Dissorophus. The ulnare of Acheloma cumminsi (Fig. 4) is very similar to that of Dissorophus. There are two distinct articular surfaces along the medial edge: one for the ulna and a second for the intermedium. The rim along the dorsal side of the contact surface for the intermedium is raised. The same edge on the ulnare of Dissorophus is also raised, but only slightly. Distal to the contact surface for the intermedium, the edge of the ulnare is concave as in Dissorophus.

Intermedium: The intermedium of Eryops has a deep V-shaped notch (Fig. 1A, B) interpreted by Gregory et al. (1923) as fitting against the lateral corner of the distal end of the radius, and as a consequence displacing the ulna proximally relative to the radius. This configuration requires the radius to have both a laterally facing articular surface and a distal articular surface for the intermedium. However, the radius of Eryops has only a distal articular surface for the intermedium (Pawley and Warren 2006). Furthermore, placement of the proximal carpal series into their natural position shifts the notch further from the corner of the radius, not closer (Fig. 2A). While the biological significance of this notch is uncertain, it did not articulate with the radius.

Proximally, the intermedium contacts the distal end of the ulna and, contrary to Pawley and Warren (2006), has an extensive rather than narrow contact with the distal end of the radius. Medially, it contacts centrale 4. A narrow gap separating the intermedium and distal carpal 4 lies in approximately the same location as the opening restored between the intermedium and ulnare by Gregory et al. (1923). When the ulnare and intermedium articulate, the lateral side of the ulnare is oriented towards the caudal end of the body contributing to a pronounced palmar concavity of the carpus (Fig. 2B). The distal end of the ulna with its separate medial and lateral surfaces for the intermedium 

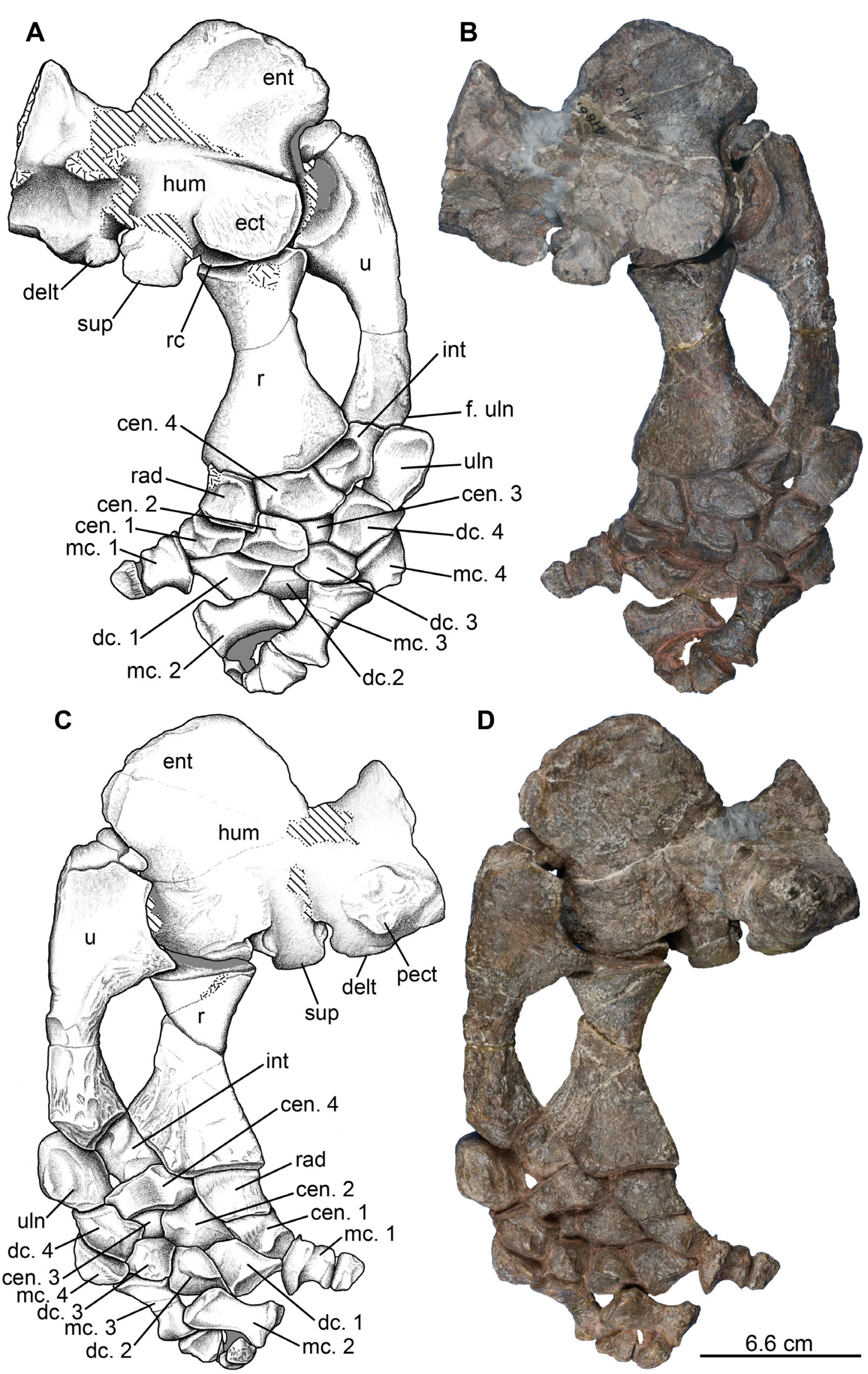

Figure 1. Left front limb of Eryops megacephalus (AMNH FARB 4186), early Permian of Texas (Wichita Group, Petrolia Formation). Illustration (A) and photograph (B) in dorsal view. Illustration (C) and photograph (D) in ventral view. 


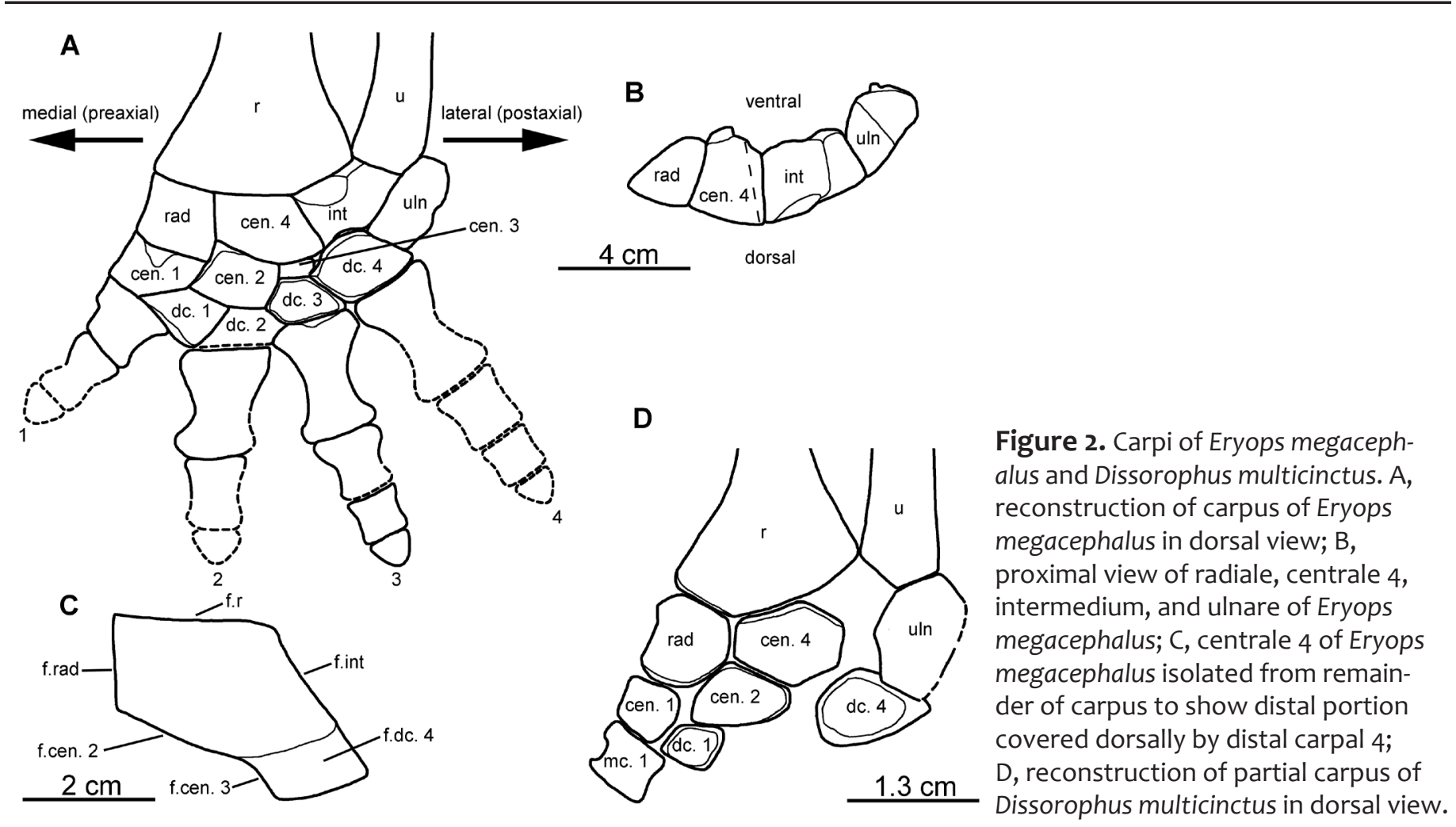

and ulnare, respectively (Pawley and Warren 2006) also indicate a more caudal position for the ulnare.

An intermedium could not be identified in specimens of Dissorophus (Fig. 3). The intermedium in Acheloma (Fig.

4 ) is a square bone wedged between the radius and ulna contacting, in addition to the radius and ulna, centrale 4 and the ulnare. It is a small bone comprising approximately one-half the length of the ulnare whereas the intermedium and ulnare are approximately equal in length in Eryops. In accordance with the relatively smaller size of the intermedium in Acheloma, there is a wide separation between the intermedium and distal carpal 4.

Centrale 4: Centrale 4 of Eryops has six distinct articular facets (Fig. 2C). The largest is the proximal contact with the radius. Medially, centrale 4 meets the radiale and laterally the intermedium. Distally, a trio of smaller surfaces contact, in medial to lateral sequence, centrale 2 , centrale 3 , and distal carpal 4. The distal surfaces for centralia 2 and 3 are flat. Centrale 4 has a rectangular lateral extension that underlaps the ventral surface of distal carpal 4 (Fig. 2A, C). Two surfaces of this lateral extension contact distal carpal 4 : a convex surface on the lateral and ventral sides and a flat dorsal surface. Contact between centrale 4 and the radius crosses a sharply angled edge on the distal end of the radius that is a continuation of the radial flexor ridge (Pawley and Warren 2006). This edge divides the distal surface of the radius into two distinct facets: one for the radiale and most of centrale 4 and a second for the remainder of centrale 4 and the intermedium. These two articular regions are set apart by an angle of approximately $130^{\circ}$ with the articular surface for the intermedium directed posteriorly as well as laterally. In order to fit across this edge, centrale 4 has a notched proximal surface.

Centrale 4 in Dissorophus (Figs. 2D, 3) has clearly visible contacts with the ulna, radiale, centrale 2, centrale 3 , and the intermedium as in Eryops, but a different association with distal carpal 4 . The lateral extension of centrale 4 that underlies distal carpal 4 in Eryops is absent in centrale 4 of Dissorophus and there is no facet for distal carpal 4. A slightly concave non-articular surface on centrale 4 of Dissorophus between the contacts for the intermedium and centrale 3 is not seen in Eryops. This non-articular surface faces distal carpal 4, but is clearly separated from it. One other notable difference is the absence in centrale 4 of Dissorophus of the strong ventral curvature in Eryops.

Centrale 4 in Acheloma is the largest of the centrale bones lying along the distal end of the radius between the radiale and intermedium (Fig. 4). Its distal margin is curved with a pair of distinct facets for centrale 2 and centrale 3 as in Eryops and Dissorophus.

Radiale: The radiale is similar in Eryops (Figs. 1, 2A, B), Dissorophus (Figs. 2D, 3), and Acheloma (Fig. 4). It has a square outline with a slightly concave medial edge. The cross-sectional profile of the radiale of Eryops is wedgeshaped and tapers to the medial edge. The extensive contact with the radius in Eryops occupies most of the distal surface medial to the radial flexor ridge. 

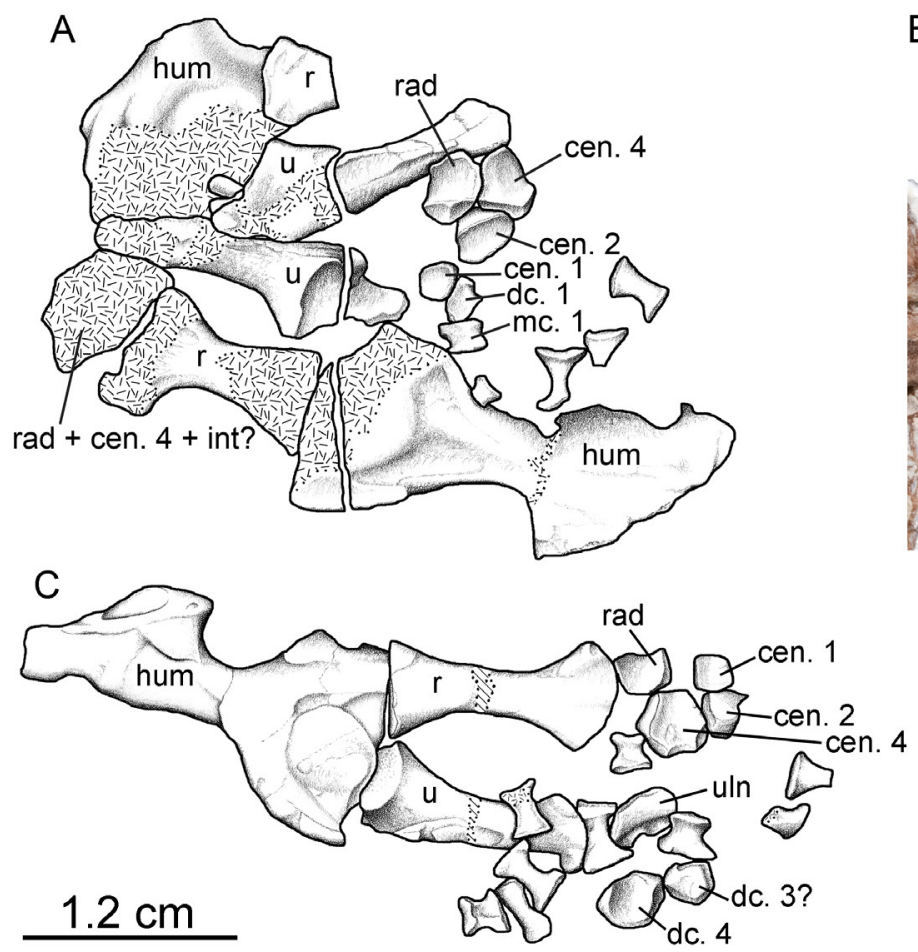
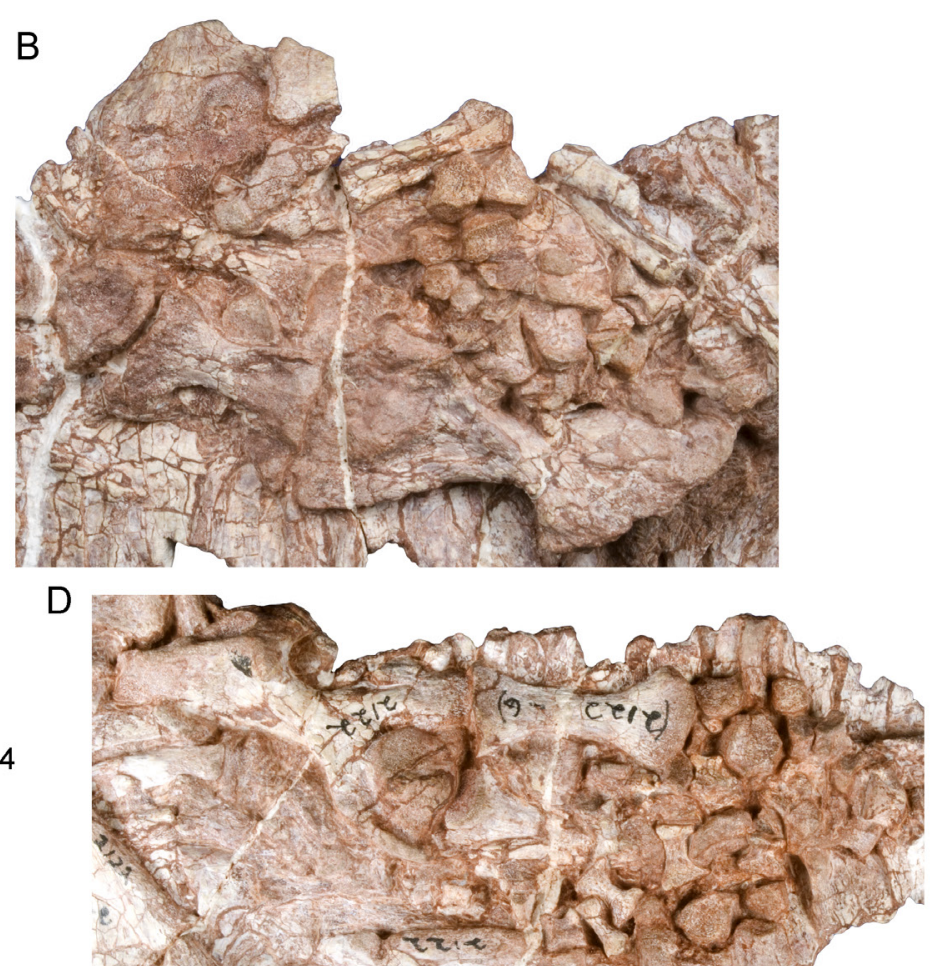

Figure 3. Partial right front limbs of Dissorophus multicinctus, early Permian of Texas (Clear Fork Group). Illustration (A) and photograph (B) of MCZ 4172. Illustration (C) and photograph (D) of MCZ 4173.

Centrale 1: This carpal bone in Eryops (Figs. 1, 2A) has a flat horizontal proximal side for the radiale and a sloping lateral contact surface for centrale 2 and distal carpal 1. Distally, centrale 1 in Eryops articulates with metacarpal 1. Centrale 1 in Acheloma shares a similar shape (Fig. 4) with this element in Eryops. Contact between centrale 1 and distal carpal 1 in Dissorophus is aligned largely along the long axis of the limb (Fig. 2D) whereas the same contact surface in Eryops is set at an angle to this long axis (Fig. $2 \mathrm{~A})$. Centrale 1 is approximately two-thirds the size of the radiale in Dissorophus but the two elements are much closer in size in Eryops and Acheloma.

Centrale 2: Centrale 2 in Eryops is a square block-shaped bone that contacts centrale 4 proximally, centrale 1 and the radiale medially, distal carpals 1 and 2 distally, and centrale 3 and distal carpal 4 laterally (Figs. 1, 2A). The dorsal surface is flat, but ventrally the surface has a deep concavity separating the rounded medial and lateral ends of the bone. This concavity is confluent with the sulcus on the intermedium. Unlike Eryops, centrale 2 of Dissorophus (Figs. 2D, 3) lacks separate facets for distal carpals 2 and 3. Centrale 2 in Acheloma has the same triangular shape (Fig. 4) as present in Dissorophus. The base of the triangle contacts centrale 1 and the radiale, and the tapering laterally portion contacts centrale 4 proximally and centrale 3 distally and laterally.

Centrale 3: Centrale 3 is the smallest of the carpals in Eryops wedged between centralia 2 and 4 and distal carpals 2 and 3 (Figs. 1, 2A). Its dorsal face is rectangular with a longer medio-lateral dimension, contrary to the restoration of Gregory et al. (1923) in which the bone is shown as proximo-distally elongate. Centrale 3 could not be identified in either specimen of Dissorophus (Fig. 3). Centrale 3 in Acheloma is a diamond-shaped bone (Fig. 4) and a relatively larger carpal bone than in Eryops. In the former, centrale 3 is the same size as centrale 2 whereas in the latter it is much smaller.

Distal carpal 1: This is a rectangular bone in Eryops with a tapering medio-distal corner (Figs. 1, 2A) and shares with centrale 1 a distal contact with metacarpal 1 . Its proximal contact with centrale 2 is broad medio-laterally and dorso-ventrally. Distal carpal 1 is similar in Dissorophus (Figs. 2D, 3) and Eryops. Plaster obscures the lateral side of distal carpal 1 in Acheloma, but the bone is clearly tall and rectangular (Fig. 4).

Distal carpal 2: Distal carpal 2 in Eryops has a flat dorsal side and strongly convex ventral side (Figs. 1, 2A). The distal contact surface for metacarpal 2 is smaller than the proximal surface for centrale 2 . A distal carpal 2 cannot be identified in specimens of Dissorophus (Fig. 3). Distal carpal 2 in Acheloma has a rectangular shape (Fig. 4).

Distal carpal 3: Distal carpal 3 in Eryops has a suite of contact points for distal carpal 4 laterally, centralia 2 and 3 proximally, distal carpal 2 medially, and the third metacarpal distally. Its dorsal side is slightly concave and the ventral side strongly convex. A polygon-shaped bone next to distal carpal 4 in MCZ 4173 of Dissorophus (Fig. 3C, 


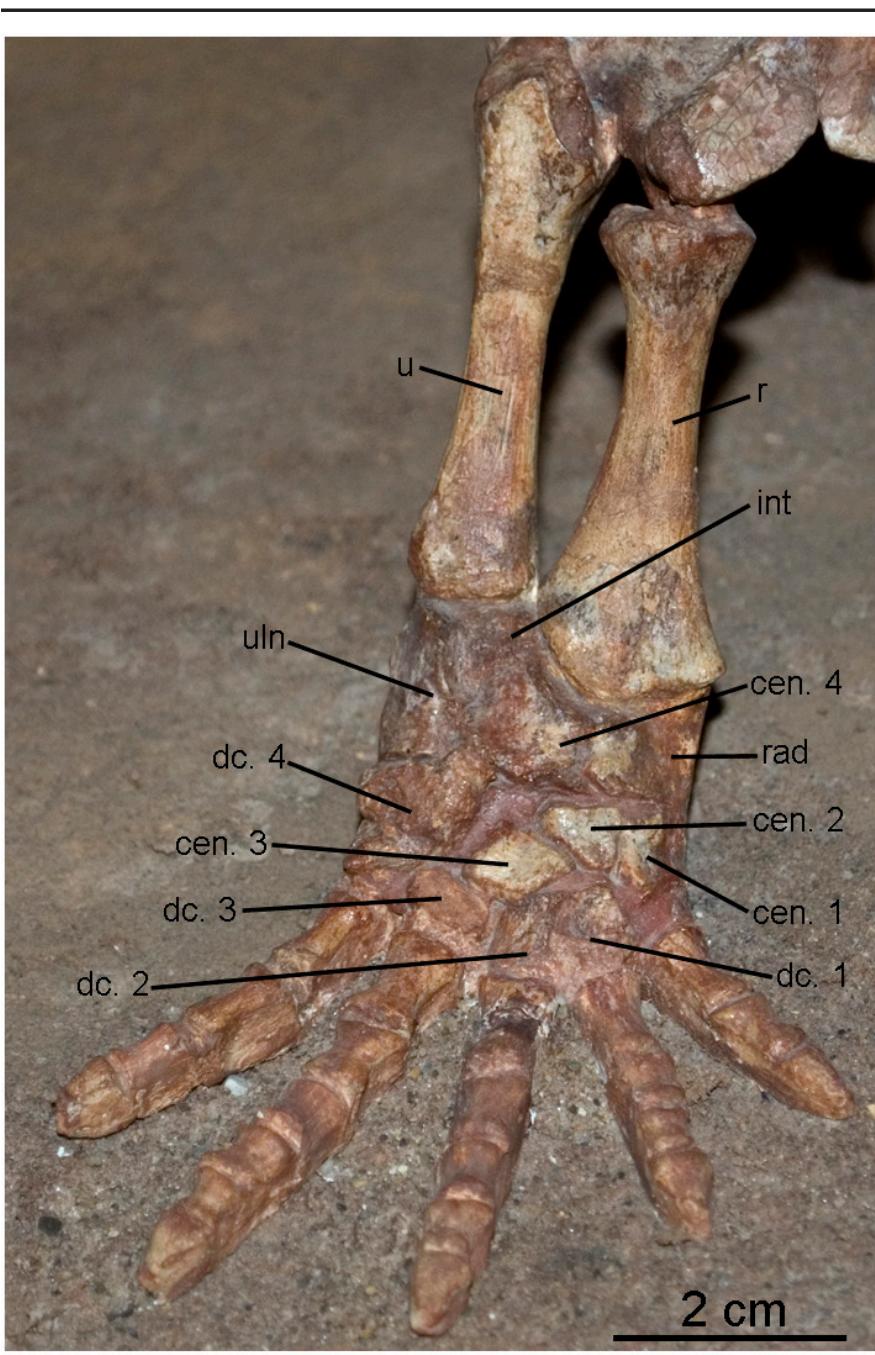

Figure 4. Right front limb of Acheloma cumminsi (FMNH UC 1756).

D) is possibly a distal carpal 3. It is not included in the reconstruction of the carpus because identify and proper orientation of this bone are uncertain. Acheloma has an oval distal carpal 3 (Fig. 4).

Distal carpal 4: Distal carpal 4 shares a similar shape in Eryops, Dissorophus, and Acheloma. It has a wider medial side contacting centrale 3 and centrale 4 and a tapering lateral end contacting the ulnare proximally and metacarpal 4 distally (Figs. 1-4). The dorsal side is concave in these genera and ventral side convex in Eryops.

\section{Metacarpals}

Two brief points regarding metacarpal 1 of Eryops are not apparent from the description or illustration in Gregory et al. (1923). First, metacarpal 1 is asymmetric along its proximo-distal axis (Fig. 1). The proximal end has a large flattened medial corner and a more typical slender rounded lateral corner. The distal end may also be asymmetric, but the medial corner is incomplete. Second, the proximal and distal articular surfaces are not parallel, but diverge at a small angle of approximately $10^{\circ}$. In conjunction with the more medially facing facets on centrale 1 and distal carpal 1 for metacarpal 1 , there is a medial divergence of digit 1 whereas digits $2-4$ either point anteriorly or antero-laterally.

\section{Tarsus}

Tibiale: The tibiale of Acheloma is rectangular with a slightly concave lateral edge (Fig. 5) rather than a relatively squat bone with a strongly concave lateral margin (Schaeffer 1941). The proximal and distal contact surfaces for the tibia and centrale 1, respectively, are extensive with the proximal surface inclined towards the center of the tarsus. The distal articular surface for centrale 1 is transverse. The contact surface on the tibiale for centrale 4 is concave, as observed by Schaeffer. A bone identified herein as the tibiale of Eryops is no longer embedded in matrix (Fig. 6C), but held in position by plaster. Hence, its identification is less certain than those in articulation. However, its shape and size relative to the tibia, centrale 4, and centrale 1 matches that of the tibiale in Acheloma, although its proximo-distal length relative to the width is smaller than the tibiale of Acheloma, and the length of the unfinished side facing centrale 4 matches the length of the corresponding side of centrale 4 . The tibiale of Dissorophus is an elongate transversely narrow bone with a concave lateral side (Fig. 7).

Intermedium: The proximo-distally elongate intermedium of Acheloma has a wedge-shaped cross-section with the thick side next to the tibia and the tapered edge next to the fibula (Fig. 5). Constriction of the central portion relative to the proximal and distal ends forms a depression on the dorsal side noted by Schaeffer (1941) and a ventral concavity. The ventral concavity is part of the plantar arch of the tarsus. There is a large articular surface on the intermedium that contacted the tibia. The lateral and medial edges of the intermedium are concave with the more pronounced of the two concavities on the lateral side. A gap between the intermedium and fibulare probably included a passageway for a perforating artery.

The intermedium of Eryops (Fig. 6), like that of Acheloma, has a concave medial side, contact surfaces with the tibia and fibula separated by a non-articular surface, and a tapered lateral side contacting the fibulare. As in Acheloma, a perforating foramen, formed by complementary grooves on the medial edge of the intermedium and lateral edge of the fibulare, passes through the tarsus. A large facet on the tibial side of the intermedium articulates with the distal end of the tibia (Pawley and Warren 2006). A ventral depression, continuous with the concavity on the ventral surface of centrale 1 , is shallow closest to the border with the fibula and deeper along the distal contact with centrale 4 . The ventral surface of the fibulare bears a pair of ridges meeting distally to form a $\mathrm{V}$ flanked laterally by a third ridge. As in Acheloma, the fibular articulation occupies only the medial portion of 

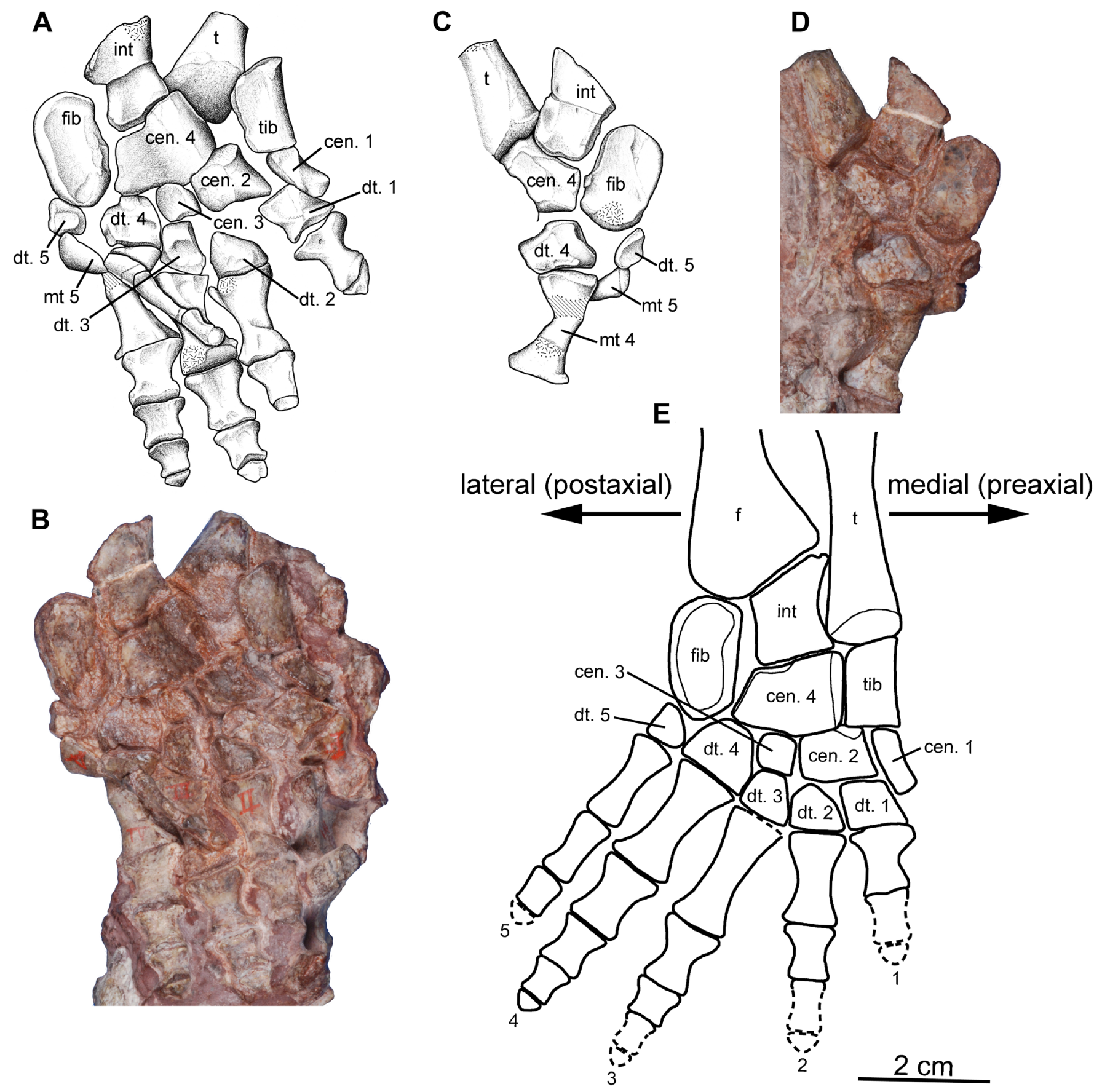

Figure 5. Pes of Acheloma cumminsi. Illustration (A) and photograph (B) of partial left crus and pes (FMNH UC 640) in ventral view. Illustration (C) and photograph (D) of FMNH UC 640 in dorsal view. E, reconstruction of pes in ventral view based on FMNH UC 640.

its medial edge. The remaining free lateral projection of the fibulare bears a concavity that probably served as the attachment site for one or more of the flexor accessorius lateralis and medialis, extensor cruris et tarsi fibularis, and abductor digit minimi (Diogo and Tanaka 2014).

Although the intermedium in specimen MCZ 4169 of Dissorophus is damaged (Fig. 7), it clearly has the same shape as the intermedium in Acheloma and Eryops including a notch in the side contacting the fibulare. This notch leads to a groove along the ventral side of the intermedium.
Fibulare: The fibulare of Acheloma has a convex lateral margin (Fig. 5) rather than flattened or slightly concave as drawn by Schaeffer (1941). The proximal end has a small contact surface for the fibula. A larger medially directed free edge forms part of the rounded medial edge. Medial and lateral edges are raised above the central region of the bone. Distally, the fibulare is V-shaped with distinct facets for distal tarsals 4 and 5 . The ventral surface of the fibulare in Eryops (Fig. 6) has a pair of ridges meeting distally to form a V flanked laterally by a third ridge. As in Acheloma, 


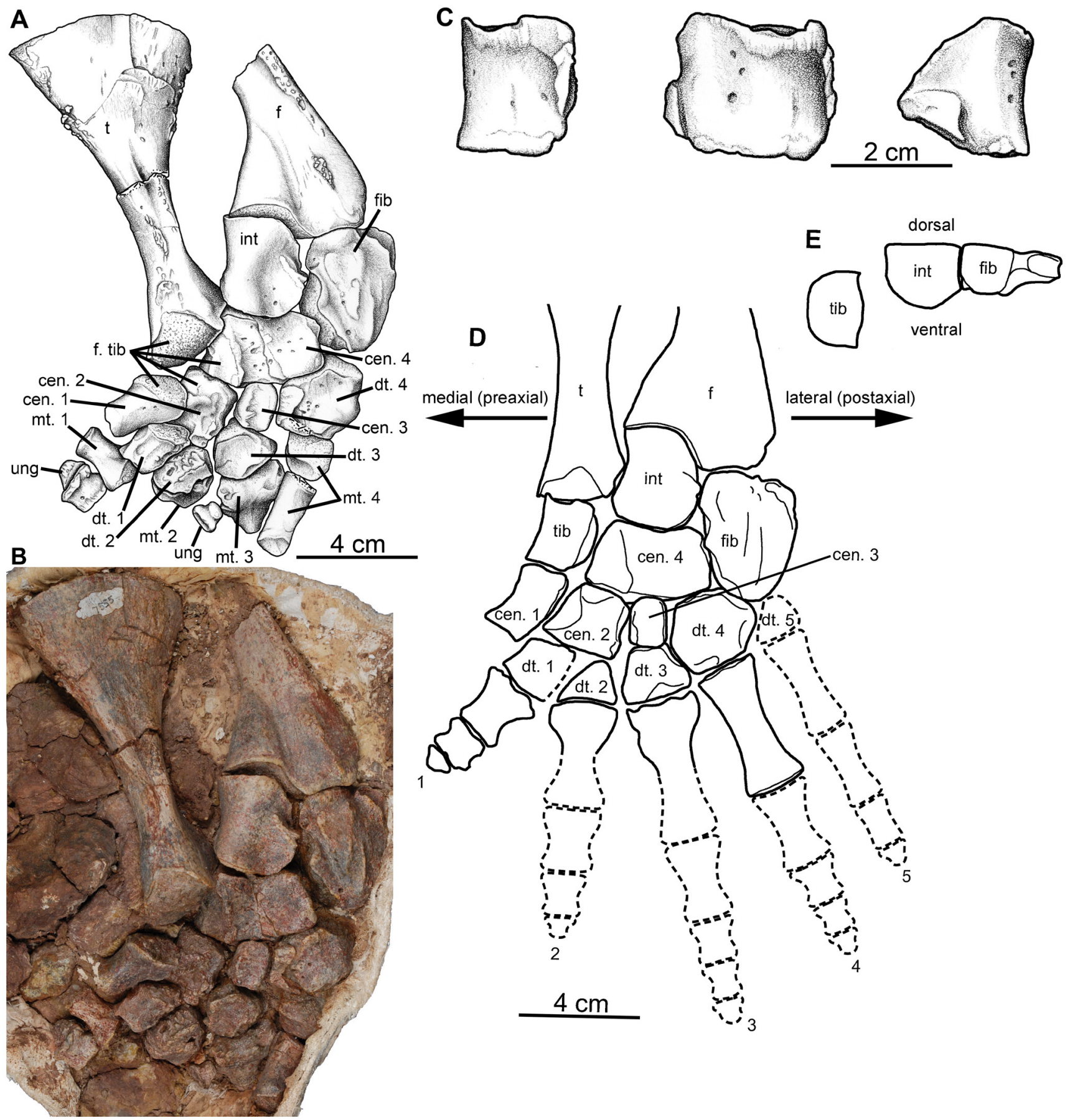

Figure 6. Pes of Eryops megacephalus. Illustration (A) and photograph (B) of partial right crus and pes (MCZ 7555) in ventral view; C, tibiale from MCZ 7555 in ventral, medial, and dorsal views; D, reconstruction of pes of Eryops megacephalus in ventral view; E, proximal view of tibiale, intermedium, and fibulare.

the fibular articulation occupies only the medial portion of its medial edge. The remaining free lateral projection of the fibulare bears a concavity that probably served as the attachment site for one or more of the flexor accessorius lateralis and medialis, extensor cruris et tarsi fibularis, and abductor digit minimi (Diogo and Tanaka 2014). The fibulare of Dissorophus (Fig. 7) is an elongate bone with raised margins bordering a concave ventral surface similar to that of Acheloma. It lacks the ridges found on the ventral side of the fibulare in Eryops. A shallow notch near the proximal corner next to the intermedium matches a similar notch in the fibulare in Eryops and Acheloma.

Centrale 4: Centrale 4 in Acheloma is a rectangular bone with its greatest length along the transverse axis (Fig. 5). The lateral edge contacting the tibiale is wider proximo-distally and dorso-ventrally than the medial edge contacting 

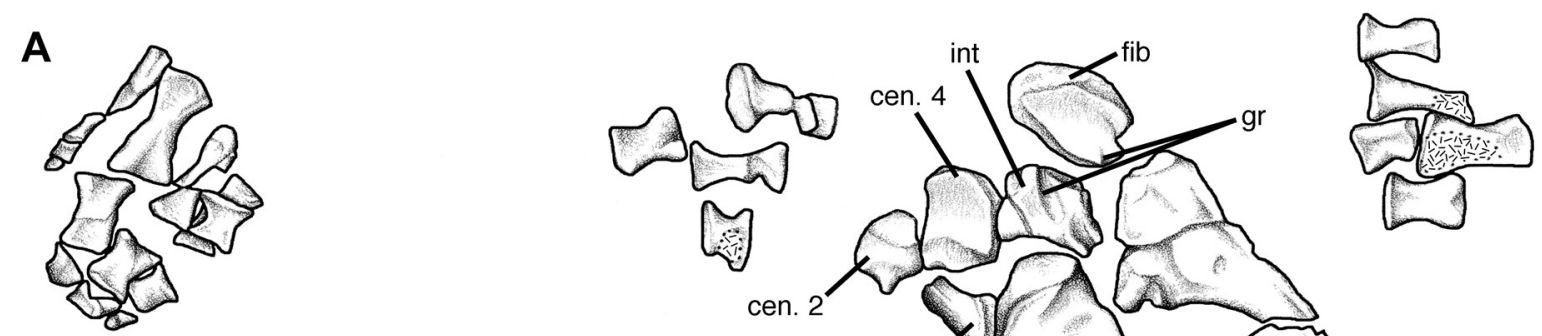

B cen. 2

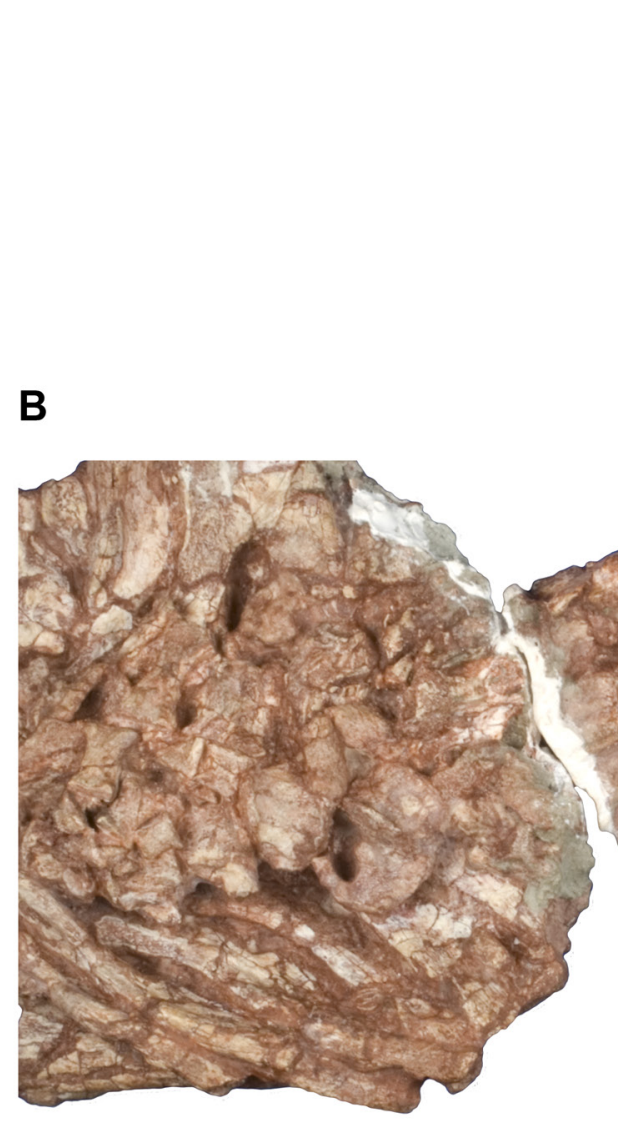

Figure 7. Partial left hind limb of Dissorophus multicinctus (MCZ 4169) in ventral view. A, illustration; B, photograph.

the fibulare. The articular surface for the tibiale continues onto the ventral side as a convex ridge. The lateral articular surface for the fibulare faces slightly ventrally and is also raised although less than that of the tibial side. Thus, the ventral curvature of the intermedium and the ventrally facing facets for the tibiale and fibulare form a deep transverse arch in the tarsus. The distal side of centrale 4 is V-shaped as noted by Schaeffer (1941), but the tip of the V is located closer to the lateral edge such that the size of the contact surface for centrale 2 is smaller than the other side of the $\mathrm{V}$ for centrale 3 and distal tarsal 4.

Proximally, centrale 4 in Acheloma has an extensive contact with the intermedium. The dorsal edge of this proximal contact is raised and there is a large dorsal exposure of the contact surface along the corner next to the tibia. The dorsal margin of the distal contact for distal tarsal 4 is also raised with a small dorsal exposure of the contact surface. The rounded ventral margin of centrale 4 for the tibiale continues dorsally suggesting a potentially large range of dorsoventral flexion along this joint.

The shape of centrale 4 in Eryops (Fig. 6) matches that in Acheloma including the broadly rounded articular end for the tibiale (crushed in MCZ 7555), a ventral concavity that is continuous with the depression on the ventral side of the intermedium, narrower proximo-distal width along fibulare side than tibiale side, and a separation distally between a surface for distal tarsal 4 and centrale 3 and another surface for centrale 2 .

Centrale 4 in Dissorophus (Fig. 7) shares the same basic morphology of centrale 4 in Eryops and Acheloma. It is a 
transversely rectangular bone with a concave ventral side formed by raised medial and lateral sides. The medial side for the tibiale is wide and the articular surface continues onto the ventral side. The proximo-distal width decreases towards the opposite end that contacts the fibulare. There is little distinction on the distal side of centrale 4 between the contact surface for centrale 2 and the common surface for centrale 3 and distal tarsal 4 .

Centrale 1: Centrale 1 in Acheloma (Fig. 5) is proximo-distally elongated (Schaeffer 1941), but FMNH UC 640 does not show any evidence that it is incomplete medially as suggested by Schaeffer, who reconstructed a cartilaginous extension. Medial edge of centrale 1 contacts the entire lateral edge of centrale 2 and the proximal section of the lateral edge of distal tarsal 1 . The distal end of centrale 1 is rounded. Schaeffer described a pretarsale in both FMNH UC 1756 and 640. A small bone next to centrale 1 in FMNH UC 640, possibly the bone mentioned by Schaeffer, appears to be a rib fragment. Centrale 1 has a similar shape in Eryops and Acheloma, but in contrast to the relatively smaller centrale 1 in Acheloma this tarsal is approximately the same size as the tibiale in Eryops (Fig. 6). Centrale 1 could not be identified in any specimen of Dissorophus (Fig. 7).

Centrale 2: Centrale 2 in Acheloma is second in size to centrale 4 (Fig. 5). It is more rectangular than shown by Schaeffer (1941) with a larger and straighter medial edge contacting centrale 3 . The lateral edge for centrale 1 is dorso-ventrally convex and proximo-distally concave. Centrale 2 has a clearly defined articular surface for the tibiale. Centrale 2 in Eryops (Fig. 6) is rectangular with the proximo-distal length slightly greater than the medio-lateral length. As in Acheloma, the proximal end is expanded dorso-ventrally where it contacts the similarly expanded tibiale end of centrale 4 . The medial-distal corner is extended between centrale 1 and distal tarsal 1. In articulation, centrale 2 is partially covered in dorsal view by the centrale 1 and distal tarsal 1. Centrale 2 in Dissorophus (Fig. 7) is a simple block of bone identified primarily by its location next to centrale 4 .

Centrale 3: Centrale 3 is the smallest of the centralia in Acheloma (Fig. 5) and Eryops (Fig. 6). Rather than triangular as described by Schaeffer (1941), centrale 3 in Acheloma (FMNH UC 640) has a square outline. Its medial and lateral contact surfaces with distal tarsal 4 and centrale 2 , respectively, are proximo-distally straight with a slight convexity on the side with distal tarsal 4 . The distal contact with distal tarsal 3 is transverse and the proximal contact with centrale 4 is slightly convex. Centrale 3 in Eryops, wedged between centrale 2 and distal tarsal 4, is more proximodistally elongate than in Acheloma. Centrale 3 could not be identified in any specimen of Dissorophus (Fig. 7).
Distal Tarsals: Of the distal tarsals in Acheloma (Fig. 5), the fifth is the smallest, and the fourth is the largest; the remaining distal tarsals are of approximately equal size. The facet on distal tarsal 4 for centrale 3 is convex in FMNH UC 640 rather than concave as described by Schaeffer (1941). There is a distinct proximal facet that fits into the dorsally concave distal edge of centrale 4 . Distal tarsal 5 is a wedge-shaped bone fitting between the fibulare and metatarsal 5. Preserved distal tarsals in MCZ 7555 of Eryops (Fig. 6) differ little from those in Acheloma. No distal tarsals can be found in specimens of Dissorophus (Fig. 7).

\section{Carpal and Tarsal Bones of Cacops aspidephorus}

FMNH UC 930 includes several isolated phalanges, carpals, and tarsals (Fig. 8). Their identification is less certain given a lack of association with a front limb or hind limb. A left fibulare (Fig. 8A) is identified by its close overall resemblance to the fibulare in Acheloma, Eryops, and Dissorophus. In each genus, the fibulare has an oval shape with separate articular surfaces for the intermedium and centrale 4. However, this separation between articular surfaces on the fibulare of Cacops occupies most of the medial margin whereas in Eryops, Dissorophus, and probably Acheloma there is a narrow gap in the form of a groove between these articular surfaces.

A slender bone with one side consisting of largely smooth bone surface and the opposite with a roughened surface and a deep longitudinal groove is possibly an intermedium of the tarsus (Fig. 8B). It is wedge-shaped with the wider side covered by finished bone except for a region of unfinished bone continuous with an unfinished end. The proximal and distal ends are slightly expanded along the wider side. Assuming this bone is an intermedium, the edge with finished bone is the medial margin that faces the tibia and the region of unfinished bone at one end of the side with finished bone is a facet for the tibia. These features are shared with the tarsal intermedium of Eryops, Dissorophus, and Acheloma.

An oval bone with one concave surface is identified tentatively as a left ulnare (Fig. 8C) based on similarities with the ulnare of Dissorophus. In both cases, the dorsal surface of the ulnare is smooth, slightly convex, and has a deep concavity along the medial edge. The ulnare of FMNH UC 930 has a broad concavity on its ventral surface. Unfortunately, this side of the ulnare is not exposed in specimen MCZ 4173 of Dissorophus, so cannot be compared.

A small disc-shaped bone with concavities on both sides (Fig. 8D) is possibly a centrale 2 or 3 of the tarsus. It also has some resemblance to distal carpal 1 of Acheloma. Similarly, a pair of smaller circular bones (Fig. 8E) is likely two smaller centralia of either the carpus or tarsus. 

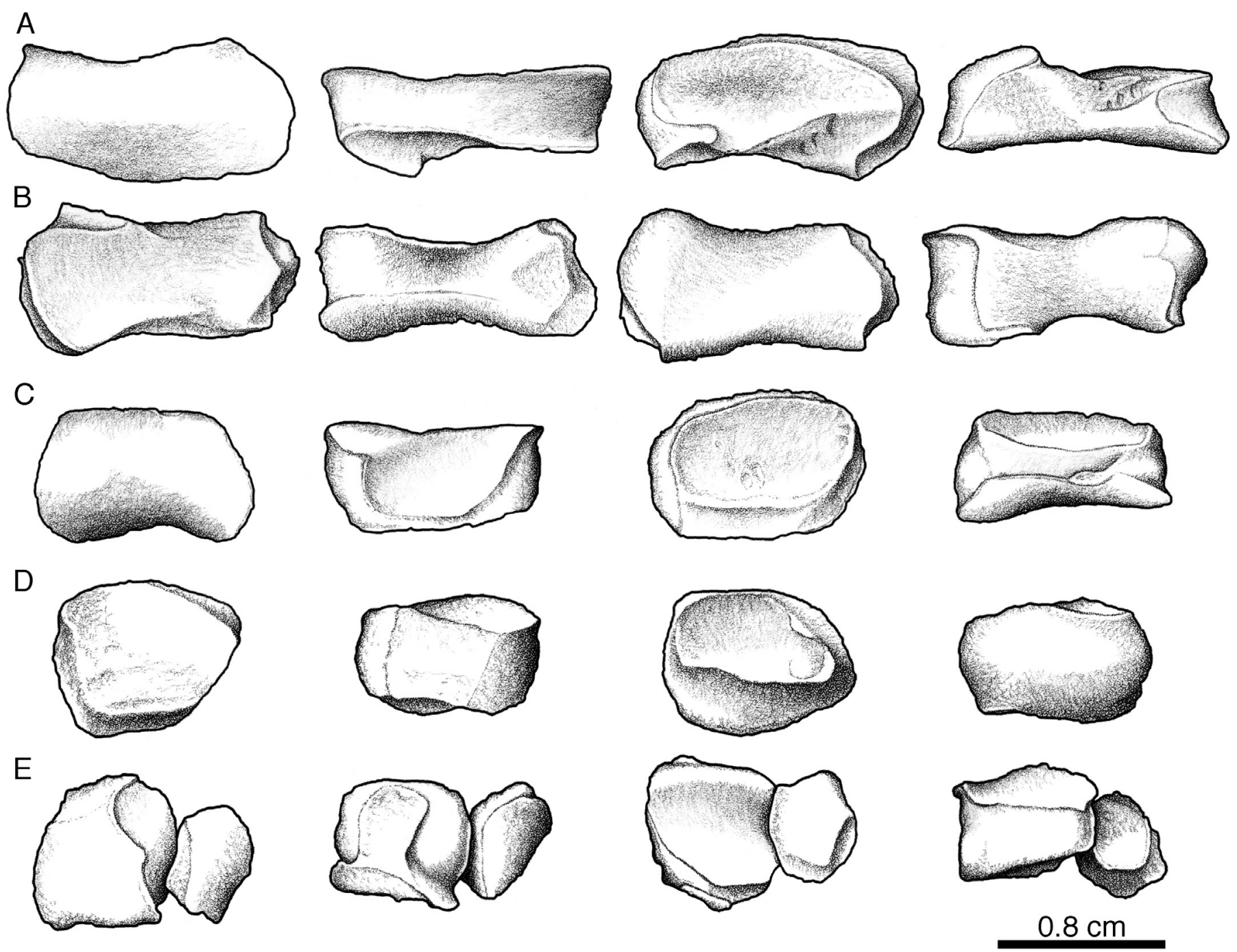

Figure 8. Carpal and tarsal bones of Cacops aspidesphorus (FMNH UC 930), Cacops bonebed. A, left fibulare; B, intermedium?; C, left ulnare?; D, centrale 2 and 3 of tarsus?; E, centralia of carpus or tarsus.

\section{DISCUSSION}

\section{Historical Importance and Previous Interpretations of AMNH FARB 4186}

Eryops megacephalus was prominent in discussions during the first half of the twentieth century on the evolution of the manus in early tetrapods primarily because a single specimen, AMNH FARB 4186 (Fig. 1), was the best example of a nearly complete and articulated front limb in a Permo-Carboniferous tetrapod. The Devonian sarcopterygian fish Eusthenopteron and Sauripterus served as the ancestral forms closest to tetrapods in numerous theoretical discussions (e.g., Gregory 1915, 1935, 1949; Gregory et al. 1923; Gregory and Raven 1941). Developmental studies on modern frogs and salamanders such as those by Steiner $(1921,1922)$ were also important in hypotheses of the origin of digits and the construction of the early tetrapod hand because early stages held clues for the construction of the first limbs. As noted by Clack (2009), different assumptions heavily influenced these hypotheses. One common assumption was the presence of an axis of bones in the fin or limb known as the metapterygial axis from which other elements branched. A specific set of carpals and a pentadactyl manus were also assumed to be present in the first limbs. The existence of additional digits (prepollex and postminimus) was assumed given their presence in the manus of frogs and salamanders (Huene 1922; Gregory et al. 1923; Steiner 1922). The key difficulties for hypotheses of early tetrapod limb evolution were where to place the metapterygial axis among the digits and the pattern of branches from this axis to form carpals and digits.

Understanding the nature of the deformation to AMNH FARB 4186 is critical for proper interpretation of the number of digits and how the digits articulate with the carpals and the carpals with each other. Digits of AMNH FARB 4186 are twisted towards the radius and flattening has removed most of the palmar arch to the carpus (Gregory 
et al. 1923). This flattening has displaced the ulnare from the ulna. Additional forces not described by Gregory et al. (1923) apparently acted on this specimen. As a result, the radiale, centrale 4 , and intermedium are shifted laterally, indicated in ventral view by a separation of articular surfaces between the radiale and centrale 4 and the radius (Fig. 1 C, D). Centralia 1, 2, and 3 and distal carpal 4 have been rotated to expose portions of their proximal articular surfaces on the dorsal side of the carpus (Fig. 1A, B). This rotation is clear for centralia 1 and 2 and distal carpal 4, but not for centrale 3 . The dorsally visible surface interpreted in this paper as the proximal articular surface was evidently interpreted by Gregory et al. (1923) as the dorsal non-articular side, and central 3 was drawn accordingly as a proximo-distally elongate bone. Distal carpal 3 is shifted dorsally, but not rotated, to expose its proximal surface. A medial shift of the digits, in particular the most medial preserved digit, is key to an interpretation of the number of digits in Eryops. In Cope's (1888) original description of AMNH FARB 4186, a gap between two digits distal to an element identified as carpale 2 (distal carpal 1 in this paper) was interpreted as indicating a missing digit 2 and a total of five digits, a conclusion endorsed by Gregory (1915). In a different interpretation offered by Huene (1922), the first digit was displaced towards the radius away from its expected contact with distal carpal 1 to lie against a carpal named the carpale praepollicis by Huene, mediale 1 by Gregory et al. (1923), and in this paper centrale 1. The remaining digits preserved their correct positions against the other distal carpals. Gregory et al. (1923), while criticizing other aspects of the interpretation of AMNH FARB 4186 by Huene (1922), agreed that the first digit was moved postmortem away from its proper articulation with distal carpal 1 and that Eryops has four rather than five digits in the manus.

Shifting placement of the first digit from the distal end of centrale 1 (Cope, 1888) to the distal end of distal carpal 1 (Gregory et al. 1923; Huene 1922) in reconstructions of the manus of Eryops raised the question of what element (if any) articulated with centrale 1 . Huene (1922) illustrated centrale 1 with a distal end too small to accommodate digit 1 . On the other hand, Gregory et al. (1923) identified a distal articular surface on mediale 1 (centrale 1 in this paper) that he argued clearly indicated the presence of a small digit. Based upon the anatomy of extant salamanders and frogs, a prepollex was restored in articulation with centrale 1 .

It is true that the distal end of centrale 1 is too small to accommodate the proximal end of metacarpal 1 , but the metacarpal need not be restricted to a single carpal bone. In fact, the distal articular surface on centrale 1 observed by Gregory et al. (1923) is continuous with the adjacent articular surface on distal carpal 1 and their combined length equals the proximal width of the first metacarpal.
Thus, metacarpal 1 articulates with centrale 1 and the adjacent half of distal carpal 1 (Fig. 2A), and there is no need to assume postmortem lateral displacement of metacarpal 1 as hypothesized by Huene (1922) and Gregory et al. (1923). Since metacarpal 1 occupies the entire articular facet on centrale 1 , there is no room to accommodate a prepollex in Eryops.

Despite the presence of only four digits in the manus of Eryops, embryological data (e.g., Steiner 1922) on extant salamanders and frogs indicated pentadactyly as primitive for tetrapods. A flattened section of the lateral side of the ulnare of AMNH FARB 4186 supposedly provided evidence of an evolutionarily lost fifth digit. This hypothesized missing fifth digit of Eryops was initially represented by a distal carpal 5 (Gregory et al. 1923; Miner 1925), but in later publications (e.g., Gregory 1935: Gregory and Raven 1941), a small digit with two phalanges was restored in this position. Thus, Eryops with its 'lost' fifth digit provided indirect paleontological support of pentadactyly as ancestral for tetrapods, but direct evidence came from a specimen of the embolomere Diplovertebron (Watson 1926) with five preserved digits. Embolomeres were thought originally to be the earliest group of labyrinthodonts and ancestral to the rhachitomes that included Eryops (Watson 1926), but in more recent phylogenetic analyses (e.g., Ruta et al. 2003) they are recovered as stem amniotes. Polydactyly in Devonian tetrapods (Coates 1996; Coates and Clack 1990; Lebedev 1984; Lebedev and Coates 1995) suggests that a count of five digits is not plesiomorphic for tetrapods, but is a derived state that likely evolved once (Laurin 1998). The point within tetrapod evolution where digits were reduced from more than five to only five is ambiguous and there is no evidence that any clade including Temnospondyli was diagnosed by possession of five digits on the manus (Laurin 1998; Ruta et al. 2003). Consequently, five digits may be transitional (Coates 1996; Ruta et al. 2003), and there is little reason to necessarily interpret a facet on the ulnare as evidence of an ancestral fifth digit without considering other explanations.

The classic reconstruction of the manus of Eryops (Gregory et al. 1923; Miner 1925) has the proximal end of the ulnare in full articulation with the distal end of the ulna, sharing the distal end of the latter with the intermedium. A laterally facing articular surface at the distal end of the ulna was interpreted as evidence for a postminimus digit that also articulated with the proximal end of the ulnare (Gregory et al. 1923; Miner 1925; Romer 1933, 1945). If this interpretation is correct, there should be, in addition to the facet for a postminimus, distinct distal articular surfaces on the ulna for the intermedium and ulnare. However, the ulna of Eryops has only two distal surfaces, one facing medially for the intermedium and another facing laterally 
(the putative articulation for a postminimus) for the ulnare (Pawley and Warren 2006). Consequently, the flattened proximal end of the ulnare projects laterally away from the carpus (Fig. 2A) and there is no evidence of a postminimus. Muscle attachment is an alternative explanation for the surfaces on the ulnare interpreted as contact for the postminimus and distal carpal 5. This is supported by the presence of roughened bone surface similar to the rugose attachment site of the pectoralis muscle on the humerus (Fig. 1C, D). Contact surfaces between carpals or between carpals and the antebrachium are much smoother. The proximal end of the ulnare is the attachment site for the extensor antebrachii et carpi ulnaris and flexor antebrachii et carpi ulnaris in Ambystoma mexicanum which is homologous to the extensor carpi ulnaris and flexor carpi ulnaris in other tetrapods (Diogo and Tanaka 2012). Miner (1925) restored the extensor carpi ulnaris and flexor carpi ulnaris with attachments to the ulnare in Eryops. The distal surface on the ulnare for distal carpal 5 (Gregory et al. 1923) is likely for the abductor digit minimi that is also homologous across other amphibians and amniotes.

\section{Comparisons Among Temnospondyls}

Carpus: Few comparisons are possible between taxa described in this paper (Acheloma, Eryops, Dissorophus, and Cacops) and other temnospondyls because the carpus is either absent or if present then consists of simple circular or oval pieces of bone identified solely by their position relative to each other and the antebrachium. Furthermore, reference to more distantly related taxa such as Tulerpeton (Lebedev and Coates 1995) does not help because they have fewer carpals relative to temnospondyls and their homologies are uncertain.

One specimen of Dendrerpeton acadianum has a set of 10 carpals in articulation with the radius and ulna (Holmes et al. 1998). The bone identified as the ulnare is unusual in its possession of a large notch on the lateral side and square rather than rectangular shape. However, given the articulated state of the forelimb and carpals and the position of this bone next to the ulna, this identification is reasonably certain. The intermedium is a pentagon unlike the elongate rectangular intermedium in Eryops, Acheloma, and Dissorophus; however, its location between the radius and ulna supports this identification. Some of the other carpals in this specimen may be interpreted differently. A carpal next to the intermedium is identified as the radiale fused to centrale 2. However, in temnospondyls, the radiale does not articulate with the intermedium. Instead, centrale 4 separates the radiale and intermedium. This carpal is more likely centrale 4 and the radiale is missing. There are two possible interpretations of the much smaller portion thought to be a fused carpal. It may be a fused centrale and most likely centrale 3 because its smaller size relative to the carpal reinterpreted as centrale 4 and its lateral location next to the intermedium matches the size differences and relative locations of centralia 3 and 4 in Eryops. Alternatively, the supposed fused carpal may actually be the lateral extension of centrale 4 observed on centrale 4 of Eryops. The carpal identified as centrale 3 is more likely distal carpal 4 because distal carpal 4 is the only carpal to contact both the ulnare and intermedium in Eryops and Acheloma. Assuming this new identification is correct, distal carpal 4 of Dendrerpeton is similar to that of other temnospondyls in that the medial side has two separate facets for centrale 3 and distal carpal 3, and a tapering lateral side contacting the ulnare.

Identification of the remaining carpals of Dendrerpeton is problematic. A tiny bone next to those originally interpreted as a fused radiale and centrale 2 is identified as centrale 1 (Holmes et al. 1998). However, it is probably not centrale 1 because centrale 1 is larger relative to the other carpals in Eryops, Dissorophus, and Acheloma. If the larger proximal bone is actually centrale 4 with a lateral extension as in Eryops, then this bone would most likely be centrale 3 . On the other hand, if the larger bone is a fused centrale 3 and centrale 4, then the small carpal is perhaps distal carpal 1. Only the pair of larger bones identified as distal carpals are probably correctly identified if the bone distal to the ulnare is distal carpal 4 and the tiny bone is distal carpal 1 . The identity of the two smaller bones distal to the reinterpreted distal carpal 4 is uncertain; they are perhaps not part of the carpus. According to the various new interpretations presented, the radiale and centralia 1 and 2 are absent in this specimen and if the tiny carpal is centrale 3 , distal carpal 1 is also missing.

A specimen tentatively assigned to Archegosaurus decheni (Witzmann 2006; Witzmann and Schoch 2006) has several carpals. Though incompletely ossified, centrale 4 of Archegosaurus shares with Eryops and Dendrerpeton a single medial side for the intermedium. Carpals are present, but poorly ossified in temnospondyls such as Balanerpeton woodi (Milner and Sequeira 1994), Doleserpeton annectens (Sigurdsen and Bolt 2010), Eoscopus lockardi (Daly 1994), Micropholis stowi (Broili and Schröder 1937; Schoch and Rubidge 2005), Sclerocephalus haeuseri (Schoch and Witzmann 2009), and Lydekkerina huxleyi (Pawley and Warren 2005). These carpals cannot be readily compared with those in Eryops, Acheloma, Dissorophus, Cacops, and Dendrerpeton.

Tarsus: The fibulare in Acheloma (Fig. 5), Eryops (Fig. 6), Dissorophus (Fig. 7), and Eoscopus lockardi (Daly 1994) is consistent in shape. It is a proximo-distally oval bone with a similar pattern of proximal facet for the fibula, medial facets for the intermedium and centrale 4 , and distal facets 
for distal tarsals 4 and 5. The distal end tapers to a V-shape clearly separating the facets for distal tarsals 4 and 5. A notch or concavity is present along the medial edge in contact with the intermedium. Shape of the fibulare in Balanerpeton woodi varies from an irregular or circular outline to more proximo-distally elongate, but in all instances has a $\mathrm{V}$-shaped distal end (Milner and Sequeira 1994). A partial pes of the dissorophoid Ecolsonia cutlerensis has an elongate fibulare with a slight $V$-shaped distal end (Berman et al. 1985). In contrast, the fibulare in stereospondyls such as Sclerocephalus haeuseri, S. nobilis, and a specimen of either Archegosaurus decheni or Cheliderpeton is broader with a transverse dimension equal to or greater than the proximo-distal length, lacks the distal $\mathrm{V}$-shape, has little distinction between the facets for distal tarsals 4 and 5, and lacks any evidence of a notch or depression on the side contacting the intermedium (Boy 1988; Witzmann and Schoch 2006; Schoch and Witzmann 2009). The fibulare of tetrapods outside of Temnospondyli is very similar to the fibulare of stereospondyls. For example, in the colosteid Greererpeton burkemorani, the fibulare is transversely oval without distinct facets for distal tarsals 4 and 5 (Godfrey 1989).

The intermedium of Eryops, Acheloma, and Dissorophus is proximo-distally elongate with a concave medial edge of finished bone and a lateral edge with a groove or concavity that fits against a similar groove or concavity on the fibulare. The medial edge is wider than the lateral edge and there is a depression on the ventral side that lines up with a depression on centrale 4. Distal contact with the tibia faces medially and the proximal contact with the fibula faces proximally and laterally in all three taxa. The same morphology is present in the intermedium of Eoscopus, a specimen of Tersomius cf. T. texensis (Daly 1994), and Balanerpeton (Milner and Sequeira 1994; Fig. 14). The bone identified as a possible intermedium in Cacops has facets for the tibia and fibula in the same positions as on the intermedium of Eryops, Acheloma, and Dissorophus, but is more slender. The intermedium of the stereospondyls Sclerocephalus haeuseri, S. nobilis, and the tarsus attributed to either Archegosaurus decheni or Cheliderpeton is also proximo-distally elongate with similar facets for the tibia and fibula (Boy 1988; Witzmann and Schoch 2006; Schoch and Witzmann 2009). The medial edge between the tibia and fibula is concave. An intermedium in the holotype of Cheliderpeton vranyi is a simple elongate bone between the fibula and tibia with only a small free edge (Werneberg and Steyer 2002). It is uncertain if the dorso-ventral width changes in a medial to lateral direction in these stereospondyls as in Eryops, Acheloma, and Dissorophus. Only a poorly preserved fibulare is known for Ecolsonia cutlerensis (Berman et al. 1985). It is elongate with a V-shaped distal end. The elongate diamond-shaped intermedium of
Greererpeton has only a small free edge between the tibia and fibula (Godfrey 1989) unlike the larger concave free margin in temnospondyls.

The tibiale of Eryops, Acheloma, Dissorophus, Eoscopus (Daly 1994), and Balanerpeton (Milner and Sequeira 1994) is proximo-distally elongate with a straight or concave medial margin. Length of the side in contact with centrale 4 is equal to the length of the corresponding contact side of centrale 4 . Cheliderpeton vranyi may be an exception with a squat tibiale that is comparable in size to centrale 4 (Wernberg and Steyer 2002). In contrast, contact side of the tibiale for centrale 4 in stereospondyls is between one-half and three-quarters of the length of centrale 4 (Boy 1988; Witzmann and Schoch 2006). The relatively shorter tibiale of stereospondyls would preclude contact between the tibiale and centrale 2, whereas in Eryops, Acheloma, Dissorophus, and Eoscopus this contact is present. The tibiale of non-temnospondyl tetrapods such as Greererpeton (Godfrey 1989) and Proterogyrinus scheelei (Holmes 1984) is more similar to the tibiale in non-stereospondyl temnospondyls.

Centrale 4 is the largest centrale in the tarsus of temnospondyls and has a consistent shape throughout this clade including the typically incompletely ossified tarsus of stereospondyls with the possible exception of Cheliderpeton. The length of the contact side for the tibiale is greater than the length of the contact side for the fibulare. Ventrally, centrale 4 is concave and formed a portion of a transverse arch of the pes. An element labeled as a proximal centrale in a partial pes of Ecolsonia is probably centrale 4 because it articulates with the intermedium and fibulare (Berman et al. 1985:fig. 12G). The illustration of this bone shows a curved side opposite the contact with the fibulare. This rounded side matches the shape of the side contacting the tibiale in other temnospondyls. Outside of Temnospondyli, centrale 4 in taxa such as Greererpeton and Proterogyrinus has a diamond rather than rectangular shape with only a shallow ventral concavity and lacks an enlarged rounded contact edge for the tibiale (Holmes 1984; Godfrey 1989).

Centrale 1 is an elongate and narrow bone between the tibiale and distal tarsal 1 in Acheloma, Eryops, and Eoscopus (Daly 1994). In contrast, it has a square outline in stereospondyls (Boy 1988; Witzmann and Schoch 2006; Schoch and Witzmann 2009). Centrale 2 deviates from a square outline by a small extension of the medial-distal corner between centrale 1 and distal tarsal 1 in Acheloma, Eoscopus (Daly 1994), and Balanerpeton (Milner and Sequeira 1994). The morphology of this corner of centrale 2 is uncertain in Dissorophus. There is an articular facet at the proximal-medial corner of centrale 2 for the tibiale in Eryops, Acheloma, and Eoscopus (Daly 1994; Fig. 15B). Centrale 3 has few details other than being the smallest of the centralia. A bone identified as a distal centrale in 
Ecolsonia (Berman et al. 1985) is probably centrale 3 in view of its small size and its location between distal tarsal 4 and the large bone identified as centrale 4 .

Distal tarsal 4 is the most distinctive of the five distal tarsals. It is the largest and contacts distal tarsals 3 and 5, centralia 3 and 4, and the fibulare in temnospondyls such as Acheloma, Eryops, Eoscopus (Daly 1994), Ecolsonia (Berman et al. 1985), and Sclerocephalus (Boy 1988; Schoch and Witzmann 2009). One apparent exception to this temnospondyl pattern is Balanerpeton in which distal tarsal 4 is reduced in size, and centrale 3 completely separates distal tarsal 4 and centrale 4 (Milner and Sequeira 1994). Similarly, a partial pes of either Archegosaurus decheni or Chelerpeton shows a large gap between distal tarsal 4 and centrale 2 mostly occupied by centrale 3 (Witzmann and Schoch 2006). Few details are known for distal tarsal 4 in non-temnospondyl tetrapods. However, in Proterogyrinus and Greererpeton centrale 3 is situated between distal tarsal 4 and centrale 2 precluding the contact present in the tarsus of many temnospondyls (Holmes 1984; Godfrey 1989).

The pretarsale described by Schaeffer (1941) is absent in reasonably complete and articulated tarsi of Acheloma, Eryops, Eoscopus (Daly 1994), Sclerocephalus (Schoch and Witzmann 2009), and Archegosaurus (Witzmann and Schoch 2006), suggesting that, contra Schaeffer (1941), this element does not occur in any temnospondyl.

\section{Functional Morphology of the Carpus and Tarsus in Temnospondyls}

Carpus: As noted by Gregory et al. (1923) and Miner (1925, the carpus in Eryops is arched through a combination of a pronounced ventral curvature of centrale 4, a slight ventral curvature of the contact surfaces between the radiale, centrale 4 , intermedium, and the radius, and the strongly angled distal surfaces on the ulna for the intermedium and ulnare (Figs. 1C, D, 2B). The arc formed by the four digits is not symmetrical along the midline of the antebrachium and carpus. Instead, there is a lateral orientation to the manus (Fig. 2B). Third and fourth digits are directed laterally, the second digit points anteriorly, and the first digit is directed medially.

Movement between the antebrachium and proximal carpals in Eryops is limited. The flat contact surfaces between the radius and the radiale and centrale 4 fit closely. Any possible movement between the radius and centrale 4 is further constrained by the edge (represented by a dashed line in Fig. 2B) along the distal surface of the radius extending from the radial flexor ridge on the ventral side (Pawley and Warren 2006) to the point of contact between centrale 4 and the intermedium at the dorsal side. Although the intermedium does not lock against the corner of the radius as depicted by Gregory et al. (1923), the medially facing surface for the radius and laterally facing surface for the ulna preclude any significant movement between the antebrachium and intermedium. Furthermore, the curvature of the carpus places the articular surface on the intermedium for the ulna in a more ventral location relative to the radius (Fig. 2B), shifting the ulnare ventral to the intermedium. Thus, the morphology of the proximal carpus locked the intermedium to the radius and ulna. Proximal carpals are little more than distal extensions of the antebrachium.

Limited movement is also indicated by the morphology of contacts between other carpals in Eryops. The proximal surfaces of centrale 2 and 3 and distal surface of centrale 4 are flat and fit closely, although a slight convexity to the distal surface of the radiale contacting the slightly concave proximal side of centrale 1 suggests some movement. Proximal sides of distal carpals 1-3 are flat as are the distal and lateral sides of centrale 2 that contacted these distal carpals. The distal side of the ulnare is convex and articulates with a slightly concave surface on distal carpal 4. Distal carpal 4 has complex contacts with distal carpal 3, centrale 4, the intermedium, and the ulnare indicating the possibility of movement between these bones. In particular, flexion is possible between distal carpal 4 and the lateral projection of centrale 4 with its convex dorsal, lateral, and ventral articular surfaces. The line of flexion between distal carpal 4 and centrale 4 continues distally between distal carpal 4 and distal carpal 3 where the curved side of distal carpal 4 lies against a curved side of distal carpal 3. Flexion is also possible between the rounded surface of centrale 3 and distal carpal 3. The pattern of these articular surfaces and their movement suggest greater movement on the ulnar than radial side of the carpus. The lateral projection of the ulnare suggests larger lever arms for the flexor antebrachii et carpi ulnaris and extensor antebrachii et carpi ulnaris to increase flexion and extension. Digit 4 may be capable of a greater range of flexion and extension than the other three digits because there is a transverse plane of movement between metacarpal 4 and distal carpal 4 and another between distal carpal 4 and the intermedium. This greater mobility of digit 4 may include abduction by the abductor digiti minimi that given the more ventral position of the ulnare could produce posterior and lateral movement of the digit (Diogo and Tanaka 2012). Significant flexion and extension of the first three digits was probably limited to the carpal-metacarpal joint because the carpals on the radial side fit more closely. It's also clear that there is no transverse line of flexion across the carpus because any attempt to draw a transverse line would produce an undulating line between carpals and include some flat and closely fitted articular surfaces. The only clear line of flexure that transverses the width of the carpus is the distal carpal-metacarpal joints. 
Convex articular surfaces of the carpals and distal ends of the radius and ulna of Dissorophus suggest more movement between carpals and between the antebrachium and carpus than in Eryops. The different shapes of centrale 4 in Eryops and Dissorophus and absence of the lateral projection on centrale 4 of Eryops also imply a greater range of carpal flexure. One point of similarity between the carpi of Eryops and Dissorophus is the curvature between the antebrachium and proximal carpals that would contribute to a ventrally concave carpus. However, two observations indicate a shallower ventral curvature in Dissorophus. Centrale 4 of Dissorophus lacks the pronounced ventral concavity that in centrale 4 of Eryops contributes to the carpal arch. In addition, the radial flexor ridge of the radius is less prominent in Dissorophus than Eryops indicating a flatter articulation between the radius and the proximal carpals. Lacking a full complement of carpal bones, the degree of curvature is uncertain but clearly less than in Eryops. The strong proximal curvature of the carpus in Eryops can be interpreted as an adaptation for supporting the body mass of this much larger temnospondyl. A tubular-shaped object, even if only a partial tube as in the arched carpus of Eryops, is better able to support compressive stress than a bar because it has a larger second moment of area (Wainwright et al. 1982).

Tarsus: There is one striking difference between the carpus and tarsus of temnospondyls as exemplified by Eryops. The distal articular surfaces of the radius and ulna are oriented along a largely transverse line despite the pronounced curvature. However, the distal articular surfaces on the tibia for the tibiale and intermedium are aligned in a dorso-ventral direction (Pawley and Warren, 2006) with the facet for the tibiale displaced towards the plantar side of the pes relative to the transverse articular facets at the distal end of the fibula for the intermedium and fibulare. As a consequence, the tarsus of Eryops, like the carpus, has a pronounced ventral arch. However, rather than an arch equally spanning the width as in the carpus, the plantar arch of the tarsus is greatest on the tibial side along a proximal-distal line separating the tibiale and centrale 1 on the medial side from centralia 2 and 4 on the lateral side (Fig. 6E). The arch is continued towards the fibular side by the ventral curvature of centrale 4 and the intermedium. Articular surfaces on centrale 4 and centrale 2 for the tibiale and centrale 1, respectively, extend onto the ventral surfaces and indicate a line of potentially significant movement along this proximo-distal line. Dorso-ventral flexion of the tibiale against the tibia is possible given the relatively larger articular surface on the tibia for the proximal end of the tibiale. The tibiale and centrale 1 may have acted as a unit to move along their contacts with centralia 2 and 4 .

Schaeffer (1941) identified two transverse planes of flexure in the tarsus of Acheloma: one between the fibulare, cen- trale 4, and tibiale proximally and centralia 1-3 and distal tarsals 4 and 5 distally, and the other between the distal tarsals and the metatarsals. In Schaeffer's (1941:fig. 1) reconstruction, the V-shaped distal side of centrale 4 would limit flexure along this first plane because it could force centralia 2 and 3 and distal tarsal 4 together. Some movement would be possible between the fibulare and distal tarsal 4 and 5 and between the tibiale and centrale 1 . However, in the new reconstruction (Fig. 5E), the distal surface on centrale 4 is flatter, producing a straighter transverse line though the tarsus that suggests little or no resistance to flexion. Convex articular surfaces of the tarsals along this plane such as between centrale 1 and the tibiale, centrale 2 and centrale 4 , and distal tarsal 4 and the fibulare support flexure and extension along this hinge-like line. Loosely fitting tarsals with rounded articular surfaces implies movement between many individual tarsals.

Schaeffer (1941) commented that the tarsal bones of Eryops have a more cuboidal shape and a more direct contact with each other unlike the tarsals of the smaller Acheloma. This difference was interpreted as greater flexibility in the tarsus of Acheloma than in Eryops. A more consolidated tarsus in a larger temnospondyl such as Eryops could be a weight-bearing feature. Reduction in flexibility with increasing body size may be true for the carpus when one compares Eryops and the smaller Dissorophus and Acheloma, but not for the tarsus where the shapes of tarsals and extent of their articulations are similar regardless of body size and suggest roughly equal ranges of flexibility. The more distally positioned end of the tibia relative to the fibula precludes a transverse plane of flexure at the crural-tarsal junction (Schaeffer 1941), even if the tibiale, intermedium, and fibulare formed a transverse series, although these proximal tarsals could move individually against the crus. This individual movement was greatest between the tibiale and tibia and least between the intermedium and fibula. Both genera share a proximo-distal line of flexure on the fibular side of the tarsus with extensive ventral articular surfaces on centralia 2 and 4 for centrale 1 and the tibiale, respectively. Both genera also share a transverse distal tarsal-metatarsal joint.

\section{Implications of Carpal and Tarsal Anatomies for Phylogeny of Temnospondyli}

With few exceptions (e.g., Ruta and Clack 2006), the manus and pes, in particular the carpus and tarsus, have contributed little to phylogenetic analyses of temnospondyls and other early tetrapods and tetrapodomorphs (Coates 1996; Laurin and Soler-Gijón 2006; Ruta and Bolt 2006; Ruta et al. 2003; Schoch 2013). Given the scant data in the literature on the temnospondyl carpus and tarsus limited largely to the classic papers on Eryops (Gregory et 
al. 1923) and Acheloma (Schaeffer 1941), it has been difficult to identify potential synapomorphies. New data on the carpus and tarsus of Eryops, Acheloma, and Dissorophus in this paper and recent descriptions of other temnospondyls such as Eoscopus (Daly 1994) and stereospondyls (Schoch and Witzmann 2009; Witzmann and Schoch 2006) provide an opportunity to address this deficiency.

Analysis and Results: The full data set in Schoch (2013) of 72 taxa and 212 characters was modified by adding Eoscopus, combining characters 33 and 34, rescoring of several entries, and addition of nine new characters (Fig. 9). Details of these modifications are found in Appendix 1. A list of all characters used in both analyses is provided in Appendix 2. The modified full matrix consists of 73 taxa and 220 characters. A second analysis retained the 220 characters of the full matrix, but reduced the number of taxa to 48 by elimination of Onchiodon labyrinthicus, Rhineceps nyasaensis, Lydekkerina huxleyi, Edingerella madagascarensis, Watsonisuchus gunganji, Benthosuchus sushkini, Wetlugasaurus angustifrons, Parotosuchus nasutus, Eocyclotosaurus wellesi, Cyclotosaurus robustus, Eryosuchus garjainovi, Siderops kehli, Batrachosuchus browni, Laidleria gracilis, Plagiosuchus pustuliferus, Gerrothorax pulcherrimus, Trematosaurus brauni, Peltostega erici, Lyrocephaliscus euri, Platyoposaurus stuckenbergi, Lapillopsis nana, Peltobatrachus pustulatus, Broomistega putterilli, Chromatobatrachus halei,
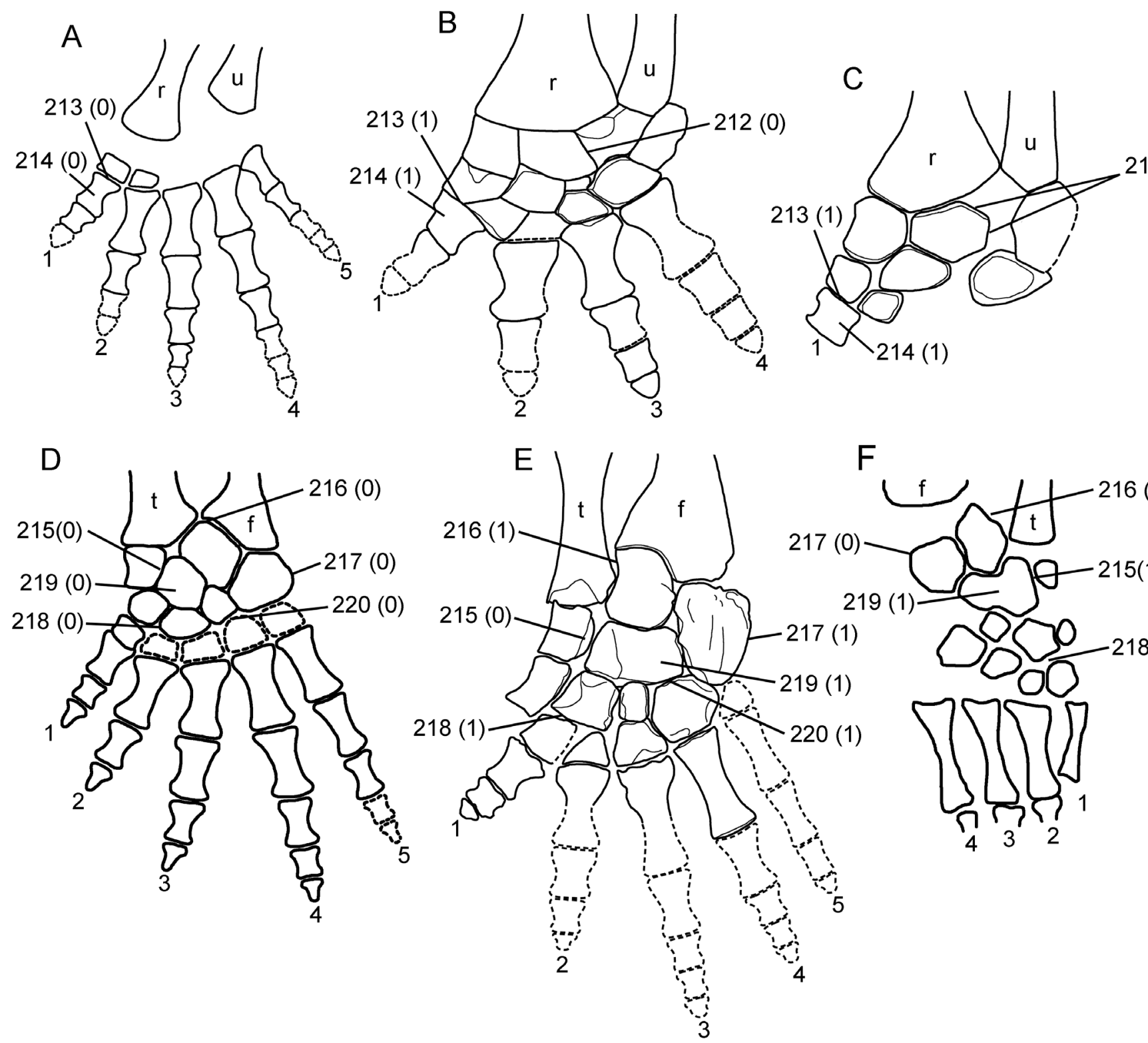

F

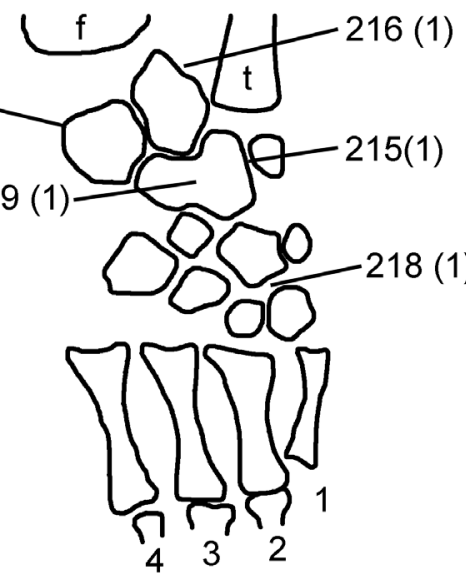

Figure 9. New characters of the carpus and tarsus. A, manus of Proterogyrinus scheelei redrawn from Holmes (1984); B, manus of Eryops megacephalus; C, manus of Dissorophus multicinctus; D, pes of Greererpeton burkemorani redrawn from Godfrey (1989); E, pes of Eryops megacephalus; F, pes of Archegosaurus decheni redrawn from Witzmann and Schoch (2006). Not drawn to scale. 
and Sangaia lavina. Many of the eliminated taxa are stereospondyls for which carpal and tarsal characters cannot be scored presently, and include some of the problematic taxa removed by Schoch in his small dataset. Schoch also eliminated Greererpeton, Capetus, and Iberospondylus in his small dataset, but these taxa are retained in my analysis because the first taxon can be scored for several of the new carpal and tarsal characters and the latter two taxa are potential early temnospondyls. The data matrix has been submitted to Morphobank [http://morphobank.org/index. php/Projects/ProjectOverview/project_id/2289].

The matrix was analyzed in PAUP* 4.0b10 (Swofford 2002). Characters 66, 74, 96, 109, 157, 169, and 181 were ordered in both analyses because the states in each character formed a progressive sequence. A heuristic search was used with parsimony as the optimality criterion, multistate taxa viewed as polymorphism, stepwise addition for starting trees, random addition sequence with 1000 replicates, and tree-bisection-reconnection selected as the branch-swapping algorithm. ACCTRAN was chosen for character state optimization. The search with the full data matrix of 73 taxa and 220 characters found 40 equally parsimonious trees of 717 steps with a CI of 0.3389 and RI of 0.7902 . The strict consensus tree is shown in Figure 10. Analysis of the smaller data matrix of 48 taxa recovered eight most parsimonious trees of 542 steps with a CI of 0.4225 and RI of 0.7709. The strict consensus tree is shown in Figure 11A. Results from both data sets are broadly comparable to the results of Schoch (2013) with the notable exception of less resolution at the base of Temnospondyli. In both results, Iberospondylus, Capetus, the clade of Dendrerpeton and Balanerpeton, and Edopoidea form part of a polytomy. In the results from the larger data set, there is an additional polytomy of the remaining individual taxa and major groups such as Dissorophoidea, Zatracheidae, Dvinosauria, Rhinosuchidae, a clade of stereospondyls minus rhinosuchids, and Eryopidae. Resolution is improved with the smaller data set although there remains a polytomy of Iberospondylus, Capetus, the clade of Dendrerpeton and Balanerpeton, Edopoidea, and similar to the results of Schoch (2013), Eryopiformes, and the clade of Dvinosauria, Zatracheidae and Dissorophoidea.

A third analysis used the data matrix from the second analysis and also removed Iberospondylus and Capetus. Parameters of the analysis were the same as those in the first two analyses. A strict consensus tree of four most parsimonious trees (Fig. 11B) shows improved resolution. The trees have a length of 534 steps, CI of 0.4288 and RI of 0.7734 . The strict consensus tree has the same basic relationships found in Schoch (2013) with the exception of Amphibamidae. These differences extend beyond the inclusion of Eoscopus that, as in Sigurdsen and Bolt (2010), is the most basal amphibamid in this study. Schoch (2013) found Doleserpeton and Gerobatrachus to form a clade with Amphibamus, Platyrhinops, and Micropholis successively more distantly related sister taxa. In sharp contrast, this study recovered a pair of monophyletic groupings consisting of Amphibamus + Doleserpeton and Gerobatrachus + Micropholis that in turn form a monophyletic group with Platyrhinops and Eoscopus as successive sister taxa to this group. However, support for the alternative relationships in this paper is weak with a bootstrap value of greater than $50 \%$ only found in one node and Bremer support values of only one or two. Support for Amphibamidae is slightly stronger than in Schoch (2013) with a pair of unambiguous characters (89 and 128) of which one (128 - palatine and ectopterygoid as narrow as maxilla) is a synapomorphy. Presence of pedicellate teeth is a synapomorphy of the clade of Amphibamus and Doleserpeton only due to the scoring of pedicely in Gerobatrachus as unknown following Marjanović and Lauren (2008).

Discussion: Despite the reduction in number of polytomies between the full data set of 73 taxa and the reduced set of 48 in the second data set, both results demonstrate considerable uncertainty among basal temnospondyls. Iberospondylus and Capetus are wild card taxa, as also identified by Schoch (2013), and in this analysis are responsible for the failure to resolve the base of Temnospondyli. Of the eight most parsimonious trees found using 48 taxa, Capetus and Iberospondylus are edopoids in two and eryopids in two others. In another pair of trees, Capetus is an edopoid and Iberospondylus is an eryopid. Finally, in the last two trees, Iberospondylus is an eryopid and Capetus falls outside of Temnospondyli along with dendrerpetontids. In the majority of trees, Iberospondylus is within Eryopidae a place higher in the cladogram than postulated by Schoch (2013). Capetus is more likely either an edopoid (four of the eight trees) or eryopid (two of eight trees), but the existence of two trees where Capetus along with Dendrerpeton and Balanerpeton fall outside of Temnospondyli reinforces the instability of basal temnospondyl relationships.

The tree derived from the third analysis is the basis for discussion of the new characters of the carpus and tarsus. Only two of the nine characters, both in the tarsus, unambiguously diagnosis clades (Fig. 12). The derived state of character 215, unequal lengths of mutual contact surfaces between the tibiale and centrale 4 reflecting the relatively smaller size of the tibiale (Fig. 9F), is diagnostic of Stereospondylomorpha (sensu Schoch 2013). It may be argued that the smaller size of the tibiale is merely evidence of the expected limited ossification of a stereospondyl tarsus, but it leaves unanswered why the other tarsals are more fully ossified. For example, shapes of centrale 4 and intermedium are similar in Archegosaurus, Sclerocephalus, Acheloma, and Eryops. Distal 


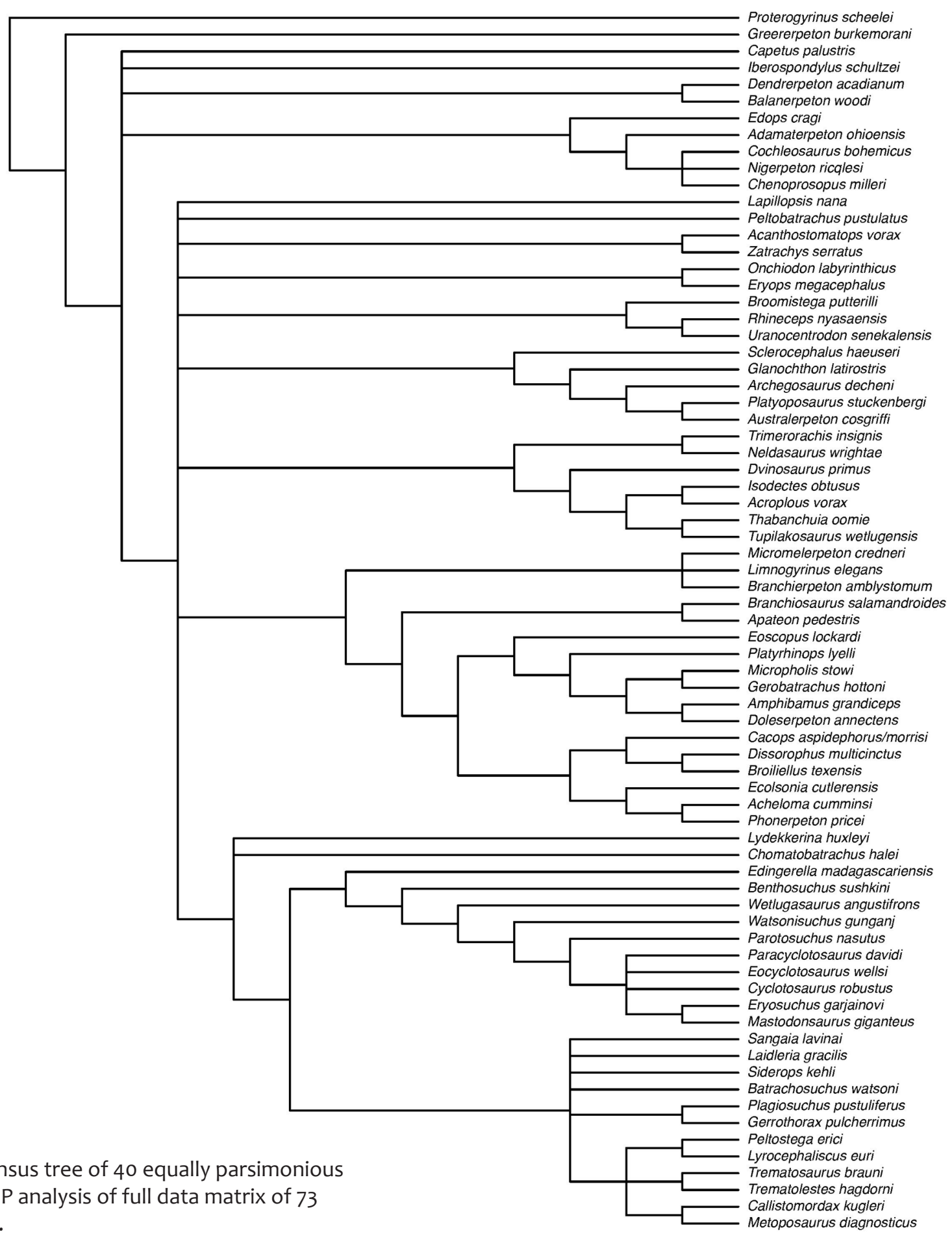

Figure 10. Strict consensus tree of 40 equally parsimonious trees derived from PAUP analysis of full data matrix of 73 taxa and 212 characters.

tarsal 4 is larger relative to distal tarsal 3 in these same genera. The close proximity of many tarsals, in particular Sclerocephalus (Boy 1988; Schoch and Witzmann 2009), suggests little room for cartilaginous portions. For these reasons, it is concluded that the relative size of the tibiale as preserved is accurate. The derived state of character 217 , fibulare with latero-medial width less than proximo-distal height (Fig. 9E), is diagnostic of Rhachitomi (sensu Schoch 2013). There is a reversal to the plesiomorphic state in Archegosaurus and Uranocentrodon.

\section{CONCLUSIONS}

Considerable anatomical detail is present in the individual bones of the temnospondyl carpus and tarsus providing data for functional and phylogenetic analyses. However, unlike many other bones of the vertebrate skeleton that 

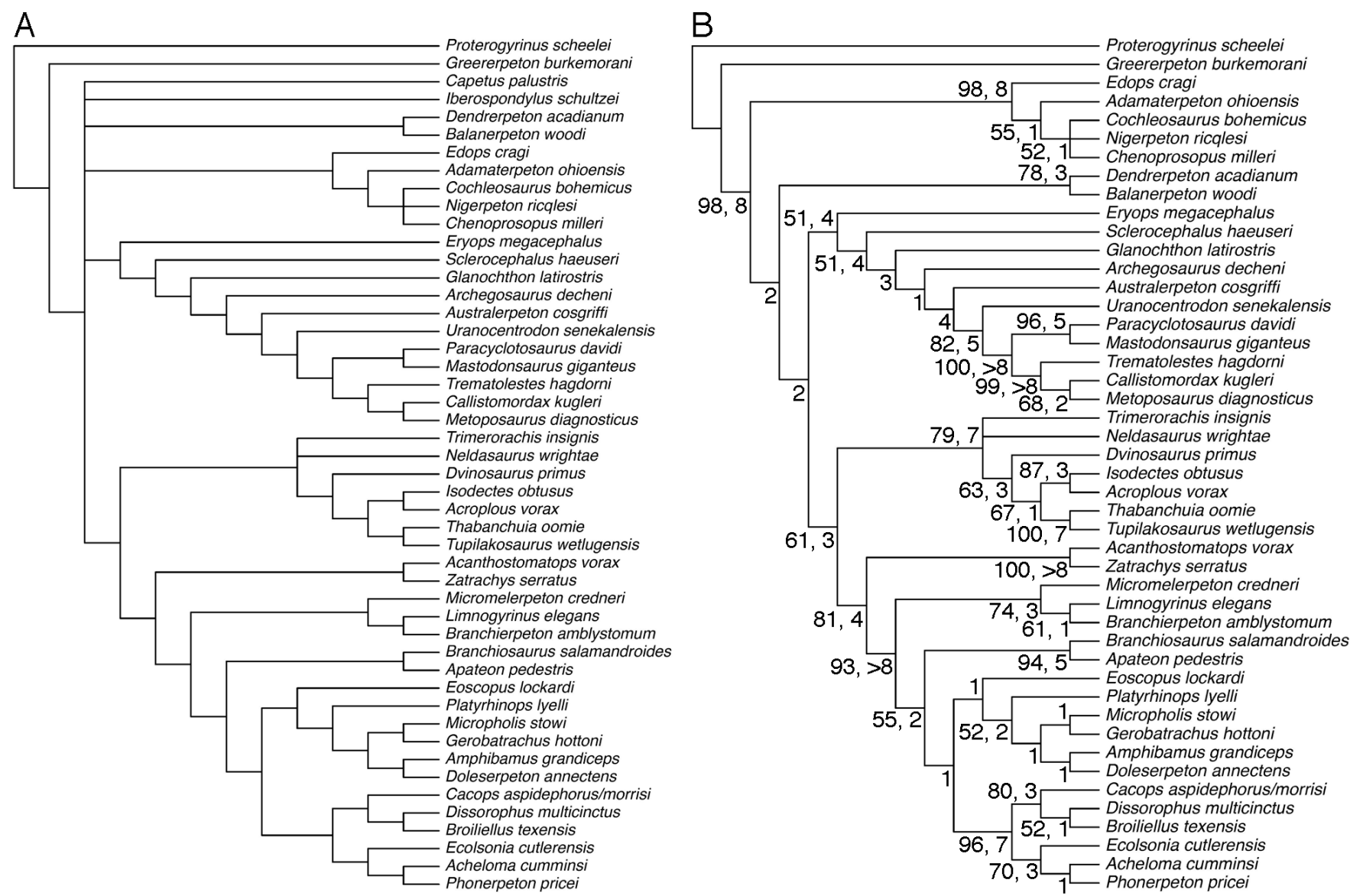

Figure 11. Results of modifications to full data matrix. A, Strict consensus tree of 8 most parsimonious trees derived from PAUP analysis of reduced data of 48 taxa and 212 characters. B, Strict consensus tree of four most parsimonious trees derived from PAUP analysis of 46 taxa and 212 characters. Numbers next to nodes are bootstrap (1000 replicates) followed by Bremer support. Any node with only a Bremer support value has a bootstrap of less than 50.

can often be identified in isolation, few carpals and tarsals can be identified outside of an articulated specimen. Bones such as the ulnare, fibulare, and the intermedium and centralia 1 and 4 of the tarsus have distinctive and consistent shapes, but others such as the smaller centralia and distal carpals and tarsals have more variable shapes (Figs. $5,6)$. In light of the relative rarity of finding a preserved autopodium with an articulated carpus or tarsus in an advanced state of ossification, it's not surprising that most of the new carpal and tarsal characters introduced in this study provide only ambiguous support for any clade and do not alter any basic relationships established in Schoch (2013). Would discovery of additional specimens provide the often-cited solution to missing data? A developmental pathway producing robust terrestrial adults is key because the carpus and tarsus are more likely to be ossified in terrestrial than in fully aquatic taxa (Schoch 2009). Dissorophids, trematopids, and amphibamids have steeper growth trajectories than aquatic taxa, and can be expected to furnish future discoveries of well-ossified carpals and tarsals. Smaller amphibamids such as Doleserpeton annectens may be problematic because their carpals and tarsals, while ossified, lack the distinctive shapes seen in dissorophids and trematopids (Sigurdsen and Bolt 2010). Other amphibamids such as Eoscopus lockardi have at least the tarsus sufficiently ossified to reveal details in individual bones for comparison with other temnospondyls (Daly 1994). Even among aquatic taxa, developmental plasticity can produce an altered pathway forming more terrestrial adults (Schoch 2014). Populations of Sclerocephalus in environmentally different lake systems can develop into large or small fully aquatic adults with poorly ossified postcranial skeletons or occasionally large terrestrial adults with robust postcranial skeletons including well-formed carpus and tarsus. In contrast, most stereospondyls remained aquatic throughout their lives and either lacked any trace of an ossified carpus or tarsus or only formed a few bones. These taxa are less likely to reveal more details of their autopodia.

To better understand the origin of Temnospondyli, defined as the least inclusive clade containing Edops and 


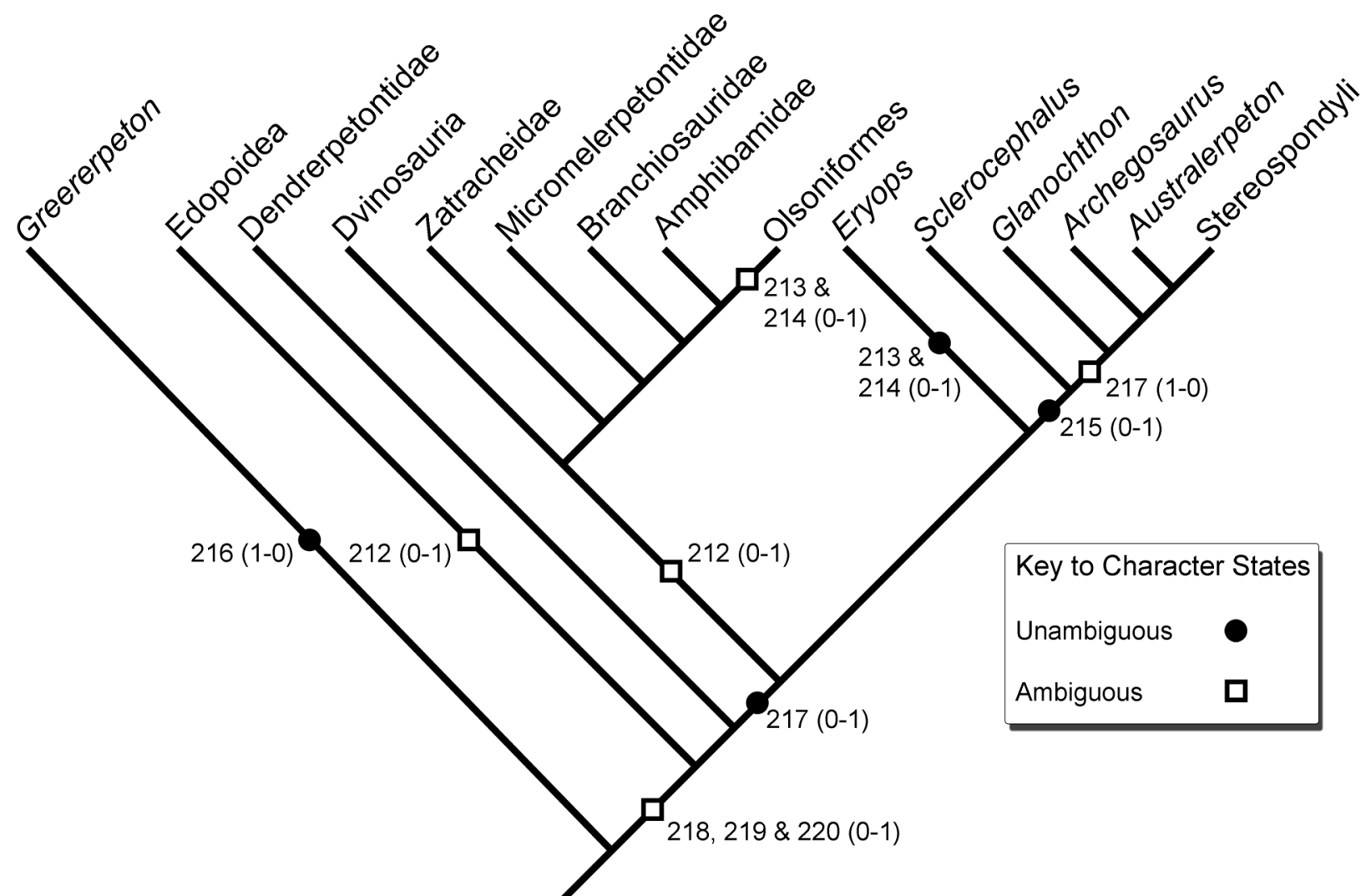

Figure 12. Simplified version of cladogram given in Figure 11B to show distribution of new carpal and tarsal characters.

Mastodonsaurus (Schoch 2013), focus should be directed on the relationships of Dendrerpeton, Balanerpeton, Capetus, and Iberospondylus to edopoids and other temnospondyls and whether any of these four genera are actually temnospondyls. Knowledge of the carpus and tarsus in these taxa would also help to clarify the plesiomorphic anatomy of the wrist and ankle in temnospondyls that, in turn, could help determine whether temnospondyls are plesiomorphically amphibious or aquatic.

\section{ACKNOWLEDGEMENTS}

I thank the following curators and assistants for the loan of specimens: C. Mehling and M. Norell (AMNH), J. Cundiff and F.A. Jenkins Jr. (MCZ), and W. Simpson and J. Bolt (FMNH). C. Mehling provided additional locality information on AMNH FARB 4186. I thank R. Schoch for sharing his data matrix on temnospondyls. Reviews by R. Holmes and S. Godfrey provided constructive comments. A Faculty Development Grant in Research from the University of Wisconsin Oshkosh provided support for this project.

\section{LITERATURE CITED}

Andrews, S. M., and T. S. Westoll. 1970. The postcranial skeleton of rhipidistian fishes excluding Eusthenopteron. Transactions of the Royal Society of Edinburgh 68:391-489.
Berman, D. S., R. R. Reisz, and D. A. Eberth. 1985. Ecolsonia cutlerensis, an early Permian dissorophid amphibian from the Cutler Formation of north-central New Mexico. New Mexico Bureau of Mines \& Mineral Resources Circular 191:1-31.

Boisvert, C. A., E. Mark-Kurik, and P. E. Ahlberg. 2008. The pectoral fin of Panderichthys and the origin of digits. Nature 456:636-638.

Boy, J. 1988. Über einige Vertreter der Eryopoidea (Amphibia: Temnospondyli) aus dem europäischen Rotliegend (? höchstes Karbon - Perm) 1. Sclerocephalus. Paläontologische Zeitschrift 62:107-132.

Broili, F., and J. Schröder. 1937. Beobachtungen an Wirbeltieren der Karrooformation. XXV. Über Micropholis Huxley. XXVI. Über Lydekkerina Broom. Sitzungsberichte der Bayerischen Akademie der Wissenschaften, MathematischNatuwisenschaftliche Abteilung 1937:19-57.

Callier, V., J. A. Clack, and P. E. Ahlberg. 2009. Contrasting developmental trajectories in the earliest known tetrapod forelimbs. Science 324:364-367.

Carroll, R. L. 1970. The ancestry of reptiles. Philosophical Transactions of the Royal Society of London 257:267-308.

Clack, J. A. 2001. Eucritta melanolimnetes from the Early Carboniferous of Scotland, a stem tetrapod showing a mosaic of characteristics. Transactions of the Royal Society of Edinburgh: Earth Sciences 92:75-95.

Clack, J. A. 2009. The fin to limb transition: new data, interpretations, and hypotheses from paleontology and developmental biology. Annual Review of Earth and Planetary Sciences 37:163-179. 
Coates, M. I. 1996. The Devonian tetrapod Acanthostega gunnari Jarvik: postcranial anatomy, basal tetrapod interrelationships and patterns of skeletal evolution. Transactions of the Royal Society of Edinburgh: Earth Sciences 87:363-421.

Coates, M. I., and J. A. Clack. 1990. Polydactyly in the earliest known tetrapod limbs. Nature 347:66-69.

Cope, E. D. 1888. On the shoulder-girdle and extremities of Eryops. Transactions of the American Philosophical Society 16:362-368.

Craddock, K. W., and R. W. Hook. 1989. An overview of vertebrate collecting in the Permian system of north-central Texas. Pp. 40-46 in Guidebook Field Trip No. 2, 49th Annual Meeting of the Society of Vertebrate Paleontology, Austin, Texas.

Daly, E. 1994. The Amphibamidae (Amphibia: Temnospondyli), with a description of a new genus from the Upper Pennsylvanian of Kansas. The University of Kansas Museum of Natural History, Miscellaneous Publication 85:1-59.

Davis, M. C., N. H. Shubin, and E. B. Daeschler. 2004. A new specimen of Sauripterus taylori (Sarcopterygii, Osteichthyes) from the Famennian Catskill Formation of North America. Journal of Vertebrate Paleontology 24:26-40.

DeMar, R. 1968. The Permian labyrinthodont amphibian Dissorophus multicinctus, and the adaptations and phylogeny of the family Dissorophidae. Journal of Paleontology 42:1210-1242.

Dilkes, D. W., and R. R. Reisz. 1987. Trematops milleri Williston, 1909 identified as a junior synonym of Acheloma cumminsi Cope, 1882, with a revision of the genus. American Museum Novitates 2902:1-12.

Diogo, R., and E. M. Tanaka. 2012. Anatomy of the pectoral and forelimb muscles of wildtype and green fluorescent protein-transgenic axolotls and comparison with other tetrapods including humans: a basis for regenerative, evolutionary and developmental studies. Journal of Anatomy 221:622-635.

Diogo, R., and E. M. Tanaka. 2014. Development of fore- and hindlimb muscles in GFP-transgenic axolotls: Morphogenesis, the tetrapod bauplan, and new insights on the ForelimbHindlimb Enigma. Journal of Experimental Zoology Part B: Molecular and Developmental Evolution 322:106-127.

Fröbisch, N. B., J. C. Olori, R. R. Schoch, and F. Witzmann. 2010. Amphibian development in the fossil record. Seminars in Cell \& Developmental Biology 21:424-431.

Gehrke, A. R., I. Schneider, E. de la Calle-Mustienes, J. J. Tena, C. Gomez-Marin, M. Chandran, T. Nakamura, I. Braasch, J. H. Postlethwait, J. L. Gómez-Skarmeta, and N. H. Shubin. 2015. Deep conservation of wrist and digit enhancers in fish. Proceedings of the National Academy of Sciences 112:803-808.

Godfrey, S. J. 1989. The postcranial skeletal anatomy of the Carboniferous tetrapod Greererpeton burkemorani Romer, 1969. Philosophical Transactions of the Royal Society of London. Series B, Biological Sciences 323:75-133.

Gregory, W. K. 1915. Present status of the problem of the origin of the Tetrapoda with special reference to the skull and paired limbs. Annals of the New York Academy of Sciences 26:317-383.

Gregory, W. K. 1935. Reduplication in evolution. The Quarterly Review of Biology 10:272-290.
Gregory, W. K. 1949. The humerus from fish to man. American Museum Novitates 1400:1-54.

Gregory, W. K., R. W. Miner, and G. K. Noble. 1923. The carpus of Eryops and the structure of the primitive chiropterygium. Bulletin of the American Museum of Natural History 48:279-288.

Gregory, W. K., and H. C. Raven. 1941. On the transformation of pectoral and pelvic paddles of Eusthenopteron type into pentadactylate limbs. Annals of the New York Academy of Sciences 42:313-327.

Hentz, T. F. 1988. Lithostratigraphy and paleoenvironments of Upper Paleozoic continental red beds, north-central Texas: Bowie (New) and Wichita (Revised) Groups. Bureau of Economic Geology, Report of Investigations 170:1-55.

Holmes, R. 1984. The Carboniferous amphibian Proterogyrinus scheelei Romer, and the early evolution of tetrapods. Philosophical Transactions of the Royal Society of London. Series B, Biological Sciences 306:431-527.

Holmes, R. B., R. L. Carroll, and R. R. Reisz. 1998. The first articulated skeleton of Dendrerpeton acadianum (Temnospondyli, Dendrerpetontidae) from the Lower Pennsylvanian locality of Joggins, Nova Scotia, and a review of its relationships. Journal of Vertebrate Paleontology 18:64-79.

Huene, F. R. v. 1922. Beiträge zur Kenntnis der Organisation einiger Stegocephalen der Schwäbischen Trias. Acta Zoologica 53:395-460.

Johanson, Z., J. Joss, C. A. Boisvert, R. Ericsson, M. Sutija, and P. E. Ahlberg. 2007. Fish fingers: digit homologues in sarcopterygian fish fins. Journal of Experimental Zoology (Mol Dev Evol) 308B:757-768.

Laurin, M. 1998. A reevaluation of the origin of pentadactyly. Evolution 52:1476-1482.

Laurin, M., and R. Soler-Gijón. 2006. The oldest known stegocephalian (Sarcopterygii: Temnospondyli) from Spain. Journal of Vertebrate Paleontology 26:284-299.

Lebedev, O. A. 1984. The first find of a Devonian tetrapod in USSR. Doklady Academii Nauk SSSR 278:1470-1473. [in Russian]

Lebedev, O. A., and M. I. Coates. 1995. The postcranial skeleton of the Devonian tetrapod Tulerpeton curtum Lebedev. Zoological Journal of the Linnean Society 114:307-348.

Marjanović, D., and M. Laurin. 2008. A reevaluation of the evidence supporting an unorthodox hypothesis on the origin of extant amphibians. Contributions to Zoology 77:149-199.

Meyer, T. E., and J. S. Anderson. 2013. Tarsal fusion and the formation of the astragalus in Hylonomus lyelli, the earliest amniote, and other early tetrapods. Journal of Vertebrate Paleontology 33:488-492.

Milner, A. R., and S. E. K. Sequeira. 1994. The temnospondyl amphibians from the Viséan of East Kirkton, West Lothian, Scotland. Transactions of the Royal Society of Edinburgh: Earth Sciences 84:331-361.

Miner, R. W. 1925. The pectoral limb of Eryops and other primitive tetrapods. Bulletin of the American Museum of Natural History 51:145-312. 
Moulton, J. 1974. A description of the vertebral column of Eryops based upon the notes and drawings of A. S. Romer. Breviora 428:1-44.

O'Keefe, F. R., C. A. Sidor, H. C. E. Larsson, A. Maga, and O. Ide. 2006. Evolution and homology of the astragalus in early amniotes: New fossils, new perspectives. Journal of Morphology 267:415-425.

Olson, E. 1941. The family Trematopsidae. Journal of Geology 49:149-176.

Pawley, K., and A. Warren. 2005. A terrestrial stereospondyl from the Lower Triassic of South Africa: the postcranial skeleton of Lydekkerina huxleyi (Amphibia: Temnospondyli). Palaeontology 48:281-298.

Pawley, K., and A. Warren. 2006. The appendicular skeleton of Eryops megacephalus Cope, 1877 (Temnospondyli: Erypoidea) from the Lower Permian of North America. Journal of Paleontology 80:561-580.

Peabody, F. E. 1951. The origin of the astragalus of reptiles. Evolution 5:339-344.

Rieppel, O. 1993. Studies on skeleton formation in reptiles. IV. The homology of the reptilian (amniote) astragulus revisted. Journal of Vertebrate Paleontology 13:31-47.

Romer, A. S. 1928. Vertebrate faunal horizons in the Texas PermoCarboniferous red beds. University of Texas Bulletin 2801:67-108.

Romer, A. S. 1933. Vertebrate Paleontology. Chicago, IL: University of Chicago Press. 491 pp.

Romer, A. S. 1945. Vertebrate Paleontology. Second Edition. Chicago, IL: University of Chicago Press. 687 pp.

Romer, A. S. 1957. The appendicular skeleton of the Permian embolomerous amphibian Archeria. Contributions from the Museum of Paleontology, University of Michigan 13:103-159.

Ruta, M., and J. R. Bolt. 2006. A reassessment of the temnospondyl amphibian Perryella olsoni from the lower Permian of Oklahoma. Transactions of the Royal Society of Edinburgh: Earth Sciences 97:113-165.

Ruta, M., and J. A. Clack. 2006. A review of Silvanerpeton miripedes, a stem amniote from the Lower Carboniferous of East Kirkton, West Lothian, Scotland. Transactions of the Royal Society of Edinburgh: Earth Sciences 97:31-63.

Ruta, M., M. I. Coates, and D. L. J. Quicke. 2003. Early tetrapod relationships revisited. Biological Reviews 78:251-345.

Sawin, H. 1941. The cranial anatomy of Eryops megacephalus. Bulletin of the Museum of Comparative Zoology 88:406-463.

Schaeffer, B. 1941. The morphological and functional evolution of the tarsus in amphibians and reptiles. Bulletin of the American Museum of Natural History 78:395-472.

Schoch, R. R. 2009. Evolution of life cycles in early amphibians. Annual Review of Earth and Planetary Sciences 37:135-162.

Schoch, R. R. 2013. The evolution of major temnospondyl clades: an inclusive phylogenetic analysis. Journal of Systematic Palaeontology 11:673-705.

Schoch, R. R. 2014. Life cycles, plasticity and palaeoecology in temnospondyl amphibians. Palaeontology 57:517-529.

Schoch, R. R., and A. R. Milner. 2000. Stereospondyli.
München, Germany: Verlag Dr. Friedrich Pfeil. 203 pp.

Schoch, R. R., and B. S. Rubidge. 2005. The amphibamid Micropholis from the Lystrosaurus Assemblage Zone of South Africa. Journal of Vertebrate Paleontology 25:502-522.

Schoch, R. R., and F. Witzmann. 2009. Osteology and relationships of the temnospondyl genus Sclerocephalus. Zoological Journal of the Linnean Society 157:135-168.

Shubin, N. H., E. B. Daeschler, and F. A. Jenkins. 2006. The pectoral fin of Tiktaalik roseae and the origin of the tetrapod limb. Nature 440:764-771.

Shubin, N. H., E. B. Daeschler, and F. A. Jenkins. 2014. Pelvic girdle and fin of Tiktaalik roseae. Proceedings of the National Academy of Sciences 111:893-899.

Sigurdsen, T., and J. R. Bolt. 2010. The lower Permian amphibamid Doleserpeton (Temnospondyli: Dissorophoidea), the interrelationships of amphibamids, and the origin of modern amphibians. Journal of Vertebrate Paleontology 30:1360-1377.

Smithson, T. R., R. L. Carroll, A. L. Panchen, and S. M. Andrews. 1994. Westlothiana lizziae from the Viséan of East Kirkton, West Lothian, Scotland, and the amniote stem. Transactions of the Royal Society of Edinburgh: Earth Sciences 84:383-412.

Steiner, H. 1921. Hand und Fuss der Amphibien, ein Beitrag zur Extremitätenfrage. Anatomischer Anzeiger 53:513-542.

Steiner, H. 1922. Die Ontogenetische und Phylogenetische Entwicklung des Vogelflügelskelettes. Acta Zoologica 3:307-360.

Swofford, D. L. 2002. PAUP* Phylogenetic Analysis Using Parsimony (*and other methods). Version 4b10. Sunderland, MA: Sinauer Associates.

Wainwright, S. A., W. D. Briggs, J. D. Currey, and J. M. Gosline. 1982. Mechanical Design in Organisms. Princeton, NJ:

Princeton University Press. 423 pp.

Warren, A., and S. Turner. 2004. The first stem tetrapod from the Lower Carboniferous of Gondwana. Palaeontology 47:151-184.

Watson, D. M. S. 1926. The evolution and origin of the Amphibia. Philosophical Transactions of the Royal Society of London, Series B, Containing Papers of a Biological Nature 214:189-257.

Werneburg, R., and J. Steyer. 2002. Revision of Cheliderpeton vranyi Fritsch, 1877 (Amphibia, Temnospondyli) from the Lower Permian of Bohemia (Czech Republic). Paläontologische Zeitschrift 76:149-162.

Williston, S. W. 1909. New or little-known Permian vertebrates: Trematops, new genus. The Journal of Geology 17:636-658.

Williston, S. W. 1911. American Permian Vertebrates. Chicago, IL: University of Chicago Press. 14599.

Witzmann, F. 2006. Cranial anatomy and ontogeny of the Permo-Carboniferous temnospondyl Archegosaurus decheni from the Saar-Nahe Basin, Germany. Transactions of the Royal Society of Edinburgh 96:131-162.

Witzmann, F., and R. R. Schoch. 2006. The postcranium of Archegosaurus decheni, and a phylogenetic analysis of temnospondyl postcrania. Palaeontology 49:1211-1235. 


\section{APPENDIX 1}

\section{Modifications to data matrix of Schoch (2013) with original numbering sequence of that paper.}

Character 26. Replaced by new character. The old character concerned the location of the orbits relative to the midline of the skull as an expression of the width of the jugals. Wide jugals for laterally placed orbits and narrow jugals for medially placed orbits. However, there is no quantification of jugal height to allow determination as either wide or narrow. The new character expresses height of the jugal relative to the height of the maxilla beneath the orbit. A jugal with a height greater than that of the maxilla would be equivalent to a wide jugal in the original character.

Character 10 for Acroplous changed from 1 to 0 because

Englehorn et al. (2008) state that the alary process is absent. It is scored as present in data matrix of Englehorn et al. (2008), but scored as ? by Ruta and Bolt (2006).

Character 13 wording changed by deletion of "separating the two alary processes" because presence of alary processes not required (e.g., Acroplous). This character is changed for Acroplous from 0 to 1 because Englehorn et al. (2008) show a large foramen identified as an anterior dorsal fenestra along the midline between the premaxillae.

Character 13 changed for Dissorophus from 0 to 1 because DeMar (1968) is incorrect. MCZ 4170 has a small fenestra.

Character 13 changed for Acheloma from 0 to 1 because the fenestra is present (Dilkes and Reisz 1987; Polley and Reisz 2011).

Character 28 changed for Balanerpeton to 0 and 1 according to Sigurdsen and Bolt (2010).

Character 28 changed for Dissorophus from ? to 1 because palpebral ossifications are present in MCZ 4186.

Character 29 changed from 1 to 0 for Dissorophus. All skulls have some distortion, but the type FMNH UC 648 has an interorbital width equal to orbital width. If Schoch (2013) is relying on DeMar (1968: text-Fig. 2), then this drawing is incorrect. The skull is crushed which has reduced the width of the orbits and the upper orbital border for the right orbit is incomplete.

Character 31 changed from 0 to 1 for Cacops based on Cacops morrisi. Character 33 is deleted and character 34 rewritten to original wording in character 32 of Englehorn et al. (2008). Character 34 of Schoch (2013) does not differentiate in state 0 between those taxa with sulci and those lacking sulci. Once this distinction is made, character 33 becomes redundant. Also, resolves the problem that numerous taxa are coded as 0 in character 35 that lack sulci. The old character 34 is now character 33 .

Character 33 changed from absence to presence for Nigerpeton because Steyer et al. (2006) describe lateral line sulci as present in adults.

Character 33 changed from absence to presence for Iberospondylus because Lauren and Soler-Gijón (2006) describe lateral line sulci as present in adults.

Character 33 changed from 1 to ? for Gerobatrachus following scoring in Anderson et al. (2008) where the only known specimen is exposed only in ventral view.
Character 34. All taxa that, according to scoring in character 33, lack lateral line sulci are rescored as - (inapplicable) rather than the original 0 score indicating presence of the sulci.

Character 34 changed from 0 to - for Acroplous because there are no lateral line sulci on the lacrimal (Foreman 1990).

Character 34 changed from 0 to - for Thabanchuia (Warren 1999) and Tupilakosaurus (Warren 1999 cites Shishkin (1973) as source for statement that Tupilakosaurus also has a palatine in place of the lacrimal) because both lack a lacrimal.

Character 35 changed from 0 to 1 for Trimerorhachis according to Case (1935).

Character 35 changed from 0 to - for Neldasaurus because the sulcus is present on the prefrontal, but not the lacrimal (Chase 1965).

Character 35 changed from 0 to - for Isodectes because the supraorbital sulcus is present along edge of prefrontal, but not on nasal or lacrimal (Sequeira 1998).

Character 35 changed from 0 to - for Acroplous because sulcus is absent on lacrimal (Foreman 1990).

Character 35 changed from 0 to - for Dvinosaurus because supraorbital sulcus is present on the nasal and prefrontal, but not lacrimal (Bystrow 1938).

Character 35 changed from 0 to - for Iberospondylus because there is only a suborbital sulcus (Lauren and Soler-Gijón 2006). Character 61 changed from 1 to ? for Siderops because this portion of the skull is not preserved in specimens studied by Warren and Hutchinson (1983).

Character 69. The order of the states was reversed to match the scoring in the data matrix.

Character 74 changed from 2 to 0 for Dissorophus based on MCZ 4170 . Character 80 changed from 1 to 0 for Gerobatrachus because the vomers lack tusks (Anderson et al. 2008).

Character 80 changed from ? to 0 for Dissorophus based on presence of vomerine denticles in MCZ 4170.

Character 80 changed from ? to 0 for Broiliellus based on presence of vomerine denticles in FMNH UC 648.

Character 81 changed from ? to 0 for Gerobatrachus based on scoring of teeth as non-pedicellate by Sigurdsen and Bolt (2010) who specifically disagreed with Anderson et al. (2008). The photograph of pedicellate teeth is not convincing.

Character 87 changed from ? to 1 for Dissorophus based on FMNH UC 648.

Character 146 changed from ? to 1 for Doleserpeton based on Sigurdsen and Bolt (2010).

Character 146 changed from ? to 0 for Dissorophus based on FMNH UC 648.

Character 146 changed from ? to 0 for Cacops based on Anderson (2005).

Character 146 changed from ? to 0 for Phonerpeton based on Dilkes (1990).

Character 146 changed from ? to 0 for Ecolsonia based on Berman et al. (1985).

Character 147 changed from ? to 0 for Doleserpeton based on Sigurdsen and Bolt (1010). These authors report denticles on probable middle coronoid, but the anterior coronoid is unknown. 
Character 147 changed from ? to 0 for Dissorophus based on FMNH UC 648.

Character 147 changed from ? to 0 for Cacops based on Anderson (2005).

Character 147 changed from ? to 0 for Phonerpeton based on Dilkes (1990).

Character 147 changed from ? to 0 for Ecolsonia based on

Berman et al. (1985).

Character 157 changed from ? to 1 for Doleserpeton based on Sigurdsen and Bolt (2010) who estimated the number of presacral vertebrae between 22 and 25 and probably 24 .

Character 157 changed from 2 to 0 for Dissorophus because DeMar (1968) estimated 25 presacrals. This number cannot be verified, but nonetheless Dissorophus has more presacrals than Cacops. My estimates also place the number at least 24.

Character 158 changed from 1 to 0 for Dissorophus because DeMar (1968) noted that the preserved portion of the tail indicate that it was long implying a tail at least as long as the presacral column.

Character 161 changed from ? to 0 for Phonerpeton based on figures in Dilkes (1990).
Character 183 changed from 0 to ? for Dissorophus because anterior edge is damaged on known interclavicles.

Character 195 changed from 0 to 1 for Proterogyrinus because distal carpals 1 and 2 are preserved (Holmes 1980).

Character 195 changed from 0 to 1 for Greererpeton because carpals are preserved although their identities are uncertain (Godfrey 1989).

Character 195 changed from 1 to ? for Gerobatrachus because there is no carpus preserved in single known specimen (Anderson et al. 2008).

Character 195 changed from 1 to ? for Ecolsonia because carpus is unknown (Berman et al. 1985).

Character 195 changed from 0 to 1 for Archegosaurus because a specimen tentatively identified as $A$. dechini has a partially ossified carpus Witzmann (2006).

Character 205 changed from 1 to 0 for Archegosaurus because Witzmann and Schoch (2006) illustrate a specimen with some ossified tarsals including a tibiale closer in shape to that of $A$. dechini than Cheliderpeton. However, there is no positive identification for this specimen.

\section{APPENDIX 2}

\section{List of Characters for Phylogenetic Analysis.}

Based on Schoch (2013) with modifications listed in Appendix 1. Numbering sequence from Schoch (2013) in parenthesis.

\section{Skull roof}

1 (1). Skull (outline). Parabolic (0) or triangular with pointed tip (1). 2 (2). Skull (height). Skull of variable height, but occiput always deeper than snout (0), or extremely flattened to equal height throughout (1).

3 (3). Ornament (elements). Reticulate ridges of various sizes (0), isolated pustules (1).

4 (4). Ornament (snout). Polygons or short grooves (0), or mostly radial, elongated grooves (1).

5 (5). Ornament (general). Shallow ridges of variable height (0), high ridges throughout (1).

6 (6). Ornament (intensive growth). Elongated ridges ('zones of intensive growth') confined to snout only (0), or prepineal growth zone established on extended anterior parietal and postorbital (1).

7 (7). Ornament (preorbital). Zone of subdued ornament on the medial skull bones adjacent to the midline suture absent (0), or present (1). (Sequeira 2003).

8 (8). Spines. Absent (0), or present along lateral flank of quadratojugal (1).

9 (9). Preorbital region (length). Less than twice the length of posterior skull table (0), or more (1).

10 (10). Premaxilla (alary process). Absent (0), or present, forming a posterior hook-like indentation (1). (Milner 1993).

11 (11). Premaxilla (prenarial portion). Short (0), or very expanded, equaling the length of the frontal (1).
12 (12). Premaxilla (outline). Parabolically rounded (0), or boxlike and anteriorly blunt (1). (Schoch and Witzmann 2009).

13 (13). Premaxillary foramen. Premaxilla and nasal completely sutured (0), or medially bearing an opening between premaxillae (1). (Boy 1972).

14 (14). Premaxillary fontanelle. Premaxillae with or without small opening $(0)$, or encircling large fenestra extending posteriorly between the nasals (1). (Boy 1989).

15 (15). Snout (internarial distance). Narrower than interorbital distance (0), or wider (1).

16 (16). Nasal (width). Nasal longer than wide (0), or as wide as long (1).

17 (17). Naris (position). At lateral margin of snout, opening laterally (0), or set well medially, opening anteriorly (1).

18 (18). Naris (extension). Naris uniform, with oval shaped margin (0), or posteriorly expanded with distinct anterior and posterior regions giving external overall "key-hole" shape (1). (Polley and Reisz 2011).

19 (19). Naris (flange). Ventral (inner) side of prefrontal, lacrimal, and nasal smooth (0), or bearing a complicated bar-like structure (narial flange) permitting contact with the antorbital bar (1).

20 (20). Nasal (lateral margin). Straight (0), or stepped, with lateral excursion anterior to lacrimal (1). (Schoch and Witzmann 2009).

21 (21). Lacrimal. Present (0), or absence (1) of lacrimal as separate ossification.

22 (22). Lacrimal (lateral suture). Parallels medial suture (0), or lateral suture posterolaterally expanded to give broader preorbital region (1).

23 (23). Lacrimal (position). Extending anterior to orbit (0), or confined to lateral orbit margin (1).

24 (24). Lacrimal (posterior extension). Restricted to the antorbital region (0), or extending back lateral to orbit (1). 
25 (25). Orbit and naris. Well separated (0), or separated only by tiny quadrangular lacrimal (1).

26 (modification of character 26). Height of jugal below orbit relative to height of maxilla. Height of jugal greater than height of maxilla (0), or height of jugal less than or equal to height of maxilla (1).

27 (27). Orbit margins. Raised well above skull plane (0), or flush with roof (1). (Damiani 2001).

28 (28). Palpebral ossifications. Ossifications in orbit restricted to sclerotic ring $(0)$, or numerous additional ossicles at medial margin of sclerotic ring (1).

29 (29). Pineal foramen. Present (0), or absent in adults (1).

30 (30). Interorbital distance. Narrower than or equalling orbital width (0), or wider (1).

31 (31). Frontal-nasal (length). Frontal as long or longer than nasal (0), or shorter (1).

32 (32). Frontal-nasal (suture). Level with or anterior to the orbit margin (0), or further posterior (1).

33 (modification of character 34). Sensory sulci. Absent from the skull roof of adults (0), extensive sensory sulci present on the skull of adults (1), sensory sulci of adults restricted to circumorbital sulcus (2). (Englehorn et al. 2008).

34 (35). Infraorbital sulcus. With simple curve on lacrimal (0), or with pronounced S-shaped lacrimal flexure (1). (Damiani 2001).

35 (36). Supraorbital sulcus. Passing entirely through nasal (0), or entering prefrontal and lacrimal (1). (Damiani 2001).

36 (37). Maxilla (anterior margin). Straight (0), or laterally convex due to enlarged teeth (1).

37 (38). Maxilla (contact to nasal). Absent, separated by lacrimal (0), or present (1).

38 (39). Prefrontal-frontal. Prefrontal substantially longer than frontal (0), or ending at one level with frontal (1).

39 (40). Prefrontal (anterior end). Pointed (0), or wide and blunt (1).

40 (41). Prefrontal (lateral suture). Straight or concave (0), or

with marked medial projection of jugal near the orbit (1).

41 (42). Prefrontal-postfrontal. Sutured (0), or separated by

frontal (1). (Damiani 2001)

42 (43). Prefrontal (process). Prefrontal-lacrimal suture simple (0), or prefrontal underlying lacrimal laterally to reach the palatine (1).

43 (44). Prefrontal-jugal. Separated by lacrimal (0), or in contact (1). 44 (45). Prefrontal-maxilla. Separated by lacrimal (0), or in contact (1). (Englehorn et al. 2008).

45 (46). Posterior skull table (length). More than 0.6 times the width (0), or less than that (1).

46 (47). Postorbital (shape). Long triangular, wedged deeply between squamosal and supratemporal (0), or short (1).

47 (48). Postorbital (end). Posterior end acutely triangular (0), or with finger-like projection (1). (Sequeira 2003).

48 (49). Postorbital. Not wider than orbit (0), or with substantial lateral process projecting into jugal (1).

49 (50). Postorbital, postfrontal. Shorter than supratemporal and parietal (0), or as long or longer (1).

50 (51). Otic notch. Semicircular embayment between squamosal and posterior skull table (0), or straight transverse posterior skull margin without embayment between cheek and table (1).
51 (52). Otic notch (position). Lateral, expanding along entire cheek to form continuous unornamented area up to quadrate (0), or slit-like (1), or small and rounded, confined to dorsomedial part of squamosal (2).

52 (53). Supratemporal. Longer than wide (0), or quadrangular, giving a foreshortened posterior skull table (1).

53 (54). Supratemporal (width). Rectangular, with straight sagittal lateral margin (0), or posterolaterally constricted by expanded otic notch (1).

54 (55). Supratympanic flange. Squamosal continuously ornamented around margin of otic notch (0), or squamosal having dorsally exposed and ornamented area (supratympanic flange) stepping abruptly into steeply aligned, poorly ornamented portion (1). (Fröbisch and Reisz 2008).

55 (56). Semilunar flange. Supratemporal without ventral projection into otic notch (0), or supratemporal forming marked ventral flange participating in medial bordering of otic notch (1). 56 (57). Jugal (ventral process). No ventral outgrowth (0), or insula jugalis framing subtemporal window (1).

57 (58). Jugal (anterior extension). Jugal ending at or behind level of anterior orbit margin (0), or extending anteriorly (1). 58 (59). Jugal-lacrimal. In contact (0), or separated by orbit or palate bones (1).

59 (60). Intertemporal. Present (0), absent (1).

60 (61). Intertemporal and postorbital. Postorbital lateral to postfrontal (0), or expanding medially to replace intertemporal, contacting parietal (1).

61 (62). Squamosal-tabular (dorsal). Separated by supratemporal $(0)$, or sutured (1).

62 (63). Tabular and squamosal. Forming either squamosal embayment or straight posterior margin (0), or projecting posteriorly, with tabular extended posterolaterally (1).

63 (64). Squamosal (falciform crest). Posterior rim of squamosal straight (0), or with convex projection, referred to as falciform crest (1).

64 (65). Tabular (horn). Present in some form (0), or entirely absent (1).

65 (66). Tabular (extension). Tabular horn pointing posteriorly if present (0), or aligned laterally (1), or sutured with squamosal posterior to otic notch (cyclotosaur condition) (2).

66 (67). Tabular (ventral crest). Absent (0), or present and shallow (1), or forming a deep ridge that almost doubles the thickness of the tabular in occipital view (2). These character-states were ordered. 67 (68). Quadratojugal (medial process). Absent (0), or present (1). 68 (69). Quadratojugal-maxilla. Separated by jugal (0), or in contact (1).

69 (70). Quadrate (dorsal process). Absent (0), or present (1).

70 (71). Posterior skull rim. Quadrate trochlea posterior to tabular horns (0), or at one level or anterior (1).

\section{Braincase and Occiput}

71 (72). Occipital flange. Descending flange of occipital portion of postparietals forming a bulge (0), or long smooth blades as long as the dermal portion of the postparietal (1).

72 (73). Postparietal-exoccipital. No contact (0), or pillar-like dorsal process of exoccipital firmly sutured to ventral side of post- 
parietal and oblique process of exoccipital sutured with ventral ramus of tabular (1).

73 (74). Postfenestral window. Large opening, having at least double the width of the foramen magnum (0), or reduced to a tiny foramen (1). (Yates and Warren 2000).

74 (75). Quadrate and occipital condyles. Quadrate condyles posterior to occipital ones (0), or at same level (1), or well anterior (2). (Yates and Warren 2000).

75 (76). Epipterygoid. Simple rod-like ascending process (0), or complicated and robust element with up to six processes (1).

\section{Dentition}

76 (77). Dentition (marginal). Heterogenous, varying sizes and distances (0), or homogeneous, small teeth, equidistant (1). (Schoch and Milner 2000).

77 (78). Dentition (upper jaw). Conical to slightly curved inwards (0), or caniniform (1). (Dilkes 1990).

78 (79). Dentition (marginal, tooth bases). Round or oval (0), or forming transversely broadened ovals (1). (Schoch and Milner 2000). 79 (80). Palatal tusks (cross-section). Round or oval (0), or laterally compressed and keeled at least on one side (1).

80 (81). Dentition (vomer). Tooth patches present at least in small specimens (0), or dentition entirely restricted to vomerine fangs (1).

81 (82). Pedicely. All teeth formed consisting of a single mineralized conus (0), or at least some teeth with two separate mineralization centers (pedicellate) (1).

82 (83). Bicuspidity. All teeth with single tip (0), or at least some with bicuspid crowns (1).

83 (84). Labyrinthodonty. Teeth with labyrinth infolding of dentine and enamel at base (0), or never labyrinthodont (1).

84 (85). Transverse tooth row (transvomerine). Absent (0), present and transverse (1), V-shaped (2).

85 (86). Additional vomerine fangs. Vomer with a single pair of fangs at the medial margin of choana (0), or with additional fangs/fang pairs posteromedially (1).

86 (87). Parasphenoid (shagreen). Tooth patches present (0), or teeth entirely absent (1). (Yates and Warren 2000).

87 (88). Ectopterygoid (fangs). Present (0), or absent (1). (Yates and Warren 2000).

\section{Palate}

88 (89). Interpterygoid vacuities. Slender and slit-like (0), or rounded, oval openings (1).

89 (90). Interpterygoid vacuities, pterygoid. Vacuities rounded bordered by moderately concave pterygoid (0), or laterally greatly extended at mid-level pushing pterygoid to the margin (1). 90 (91). Anterior palatal opening(s). Vomer and premaxilla with continuous suture (0), or perforated to accommodate symphyseal fangs (1). 91 (92). Anterior palatal opening(s). Unpaired if present (0), or paired (1).

92 (93). Vomer. Narrow and small (0), or large plate, widely separating choanae (1).

93 (94). Vomer (paired anterior depressions). Absent (0), or present (1).

94 (95). Anterior palatal depression. Posterior rim round if present (0), or straight transverse (1). (Schoch and Milner 2000)
95 (96). Vomerine ridges. Absent (0), or present, radiating from vomerine tusks anteriorly (1).

96 (97). Vomerine pit and fontanelle. Absent (0), or pit present (posterior to mandible) (1), or fenestra within such pit (2). (Schoch and Rubidge 2005, modified).

97 (98). Vomerine septum. Absent (0), or present (1). (Polley and Reisz 2011).

98 (99). Choana (lateral). Oval (0), or anterolaterally expanded with triangular outline (1).

99 (100). Choana (medial). Medial margin straight or gently convex (0), or anteromedially expanded giving choana a reniform outline (1).

100 (101). Choana (width). Elongated oval to slit-like (0), or wide round (1).

101 (102). Vomer-pterygoid. Sutured (0), or separated by palatine (1). 102 (103). Vomer (anterior part). Anterior portion shorter than behind anterior level of choana (0), or as long or longer (1).

103 (104). Vomer (extension). Vomer contacts pterygoid lateral to choana (0), or expanding posteriorly (1).

104 (105). Basipterygoid ramus. Pterygoid with short, posteromedially curved basipterygoid process, constricting palatal vacuities posterolaterally ( 0 ), or with transversely extended process producing posteriorly wider vacuities (1).

105 (106). Basicranium (contact). Joint between basal plate and pterygoid (0), or sutural contact (1).

106 (107). Basicranium, suture. Suture (if present) much shorter than basal plate, reaching at best $40 \%$ its length (0), or suture almost as long as basal plate (1).

107 (108). Parasphenoid. Suturing with exoccipitals (0), or underplating exoccipitals (1).

108 (109). Basicranium (carotids). Internal carotids entered basicranium ventrally near base of cultriform process (0), or at posterolateral corner of bone (1). (Shishkin 1968; Boy 1988). 109 (110). Parasphenoid plate. Basal plate sagittally rectangular (0), or quadrangular to wider than long (1), or much abbreviated, transversely rectangular (2). (Greatest length measured against shortest width).

110 (111). Parasphenoid plate (size). Basal plate at level posterior to basicranial joint substantially narrower than parietals (0), or as wide or wider (1).

111 (112). Cultriform process (width). Base not wider than rest, clearly set off from basal plate (0), or merging continuously into plate (1).

112 (113). Cultriform process (structure). Ventrally flat (0), or with ridge emplaced on broader base (1), or knife-edged and keel-shaped (2).

113 (114). Cultriform process (outline). Of similar width throughout (0), or posteriorly expanding abruptly to about twice the width (1).

114 (115). Cultriform process (dentition). Main shaft edentulous except for base (0), or with elongate tooth patch (1).

115 (116). Parasphenoid (posterolateral process). Posterolateral margin straight (0), or with lateral wing (1).

116 (117). Pterygoid (ventral ornament). Palatine ramus of pterygoid smooth (0), or ornamented with reticulate ridges (1). 
117 (118). Pterygoid, exoccipital. No contact (0), or sutured lateral to parasphenoid (1).

118 (119). Pterygoid, basioccipital. No contact (0), or sutured lateral to parasphenoid (1).

119 (120). Pterygoid, squamosal. Entirely sutured (0), or with open fissure (1). (Warren and Black 1985; Englehorn et al. 2008). 120 (121). Pterygoid (flange). Palatine ramus of pterygoid merging continuously into basipterygoid ramus (0), or broadening abruptly to form transverse flange (1).

121 (122). Pterygoid width. Palatine and quadrate regions forming slender rami (0), or broad shelves (1).

122 (123). Pterygoid, ectopterygoid. Palatine ramus exclusively formed by pterygoid ( 0 ), or with posteromedial projection of ectopterygoid (1).

123 (124). Pterygoid-palatine-ectopterygoid. Pterygoid contacting both ectopterygoid and palatine $(0)$, or pterygoid only in contact with ectopterygoid (1).

124 (125). Palatine, ectopterygoid. With simple, transverse suture $(0)$, or palatine with posterolateral process excluding the ectopterygoid from interpterygoid vacuity and contacting pterygoid (1).

125 (126). Palatine, vomer. Suture aligned posterolaterally (0), or with medial wing framing the interpterygoid vacuity anteriorly (1). 126 (127). Palatine (laterally exposed palatine, LEP). Absent (0), or present (1).

127 (128). Palatine, ectopterygoid (ontogeny). Maintain their width (0), or become proportionally wider (1). (Schoch and Witzmann 2009; recoded).

128 (129). Palatine, ectopterygoid (width). Much wider than maxilla (0), or as narrow (1).

129 (130). Palatine, ectopterygoid (continuous tooth row).

Absent (0), or present (1).

130 (131). Ectopterygoid (length). As long or longer than palatine (0), or markedly shorter (1).

131 (132). Ectopterygoid (laterally exposed ectopterygoid, LEE). Absent (0), or present (1).

132 (133). Ectopterygoid (Y-shaped). Ectopterygoid with continuous maxillar suture (0), or Y-shaped, with posterior half separated from maxilla by a gap (1).

133 (134). Palate structure. In occipital view, pterygoids either sloping continuously ventrolaterally or flat horizontal (0), or vertically curved ventrally at right angle with basicranium (1). 134 (135). Quadrate trochlea. Medial bulge only slightly larger than lateral one $(0)$, or being at least two times longer and twice as wide (1).

135 (136). Occipital condyle. Trilobed, with basioccipital forming ventral part of facet $(0)$, or bilobed exoccipital condyle with reduced basioccipital contribution (1).

136 (137). Exoccipital condyles. Short and broad base, projecting only with their posterior half behind the rim of the skull table (0), or almost the complete element posterior to level of occipital flange (1). 137 (138). Basioccipital (length). Forming a long element posterior to parasphenoid plate (0), or foreshortened to a narrow posterior rim of the palatal bone (1).
138 (139). Dentigerous palatal ossicles. Absent (0), or present within interpterygoid vacuities (1).

\section{Mandible}

139 (140). Postglenoid area. Absent or present as very faint outgrowth (0), or longer than glenoid facet (1).

140 (141). Postglenoid area (types). Type 1 (0), or type 2 (1). (Jupp and Warren 1986).

141 (142). Postglenoid area (dorsal). Plain (0), or with elongated groove (1).

142 (143). Hamate process. Absent (0), or present but lower than postglenoid portion is long (1), or as high as retroarticular process (2).

143 (144). Preglenoid process. Labial side of surangular with straight dorsal margin anterior to glenoid (0), or forming dorsal projection well above the level of the glenoid articulation (1).

144 (145). Meckelian window. Small round or oval opening (0), or elongate window shorter than the adductor fossa (1), or as long or longer than adductor fossa (2).

145 (146). Symphyseal teeth. No accessory teeth posterior to symphyseal tusks (0), or a transverse row of such teeth (1). (Yates and Warren 2000).

146 (147). Posterior coronoid teeth. Present (0), or absent (1). 147 (148). Anterior, middle coronoid teeth. Present (0), or absent (1).

148 (149). Mandibular osteoderms. Throat region naked (0), or covered with a mosaic of ventral osteoderms between mandible and dermal pectoral girdle (1).

\section{Visceral skeleton}

149 (150). Stapes (quadrate process). Absent (0), or present (1). 150 (151). Stapes (ventral process). Absent (0), or present, giving the proximal region two heads (1).

151 (152). Stapes (shape). Robust, tetrahedral bone with substantial quadrate process $(0)$, or rod-like element with elongated stylus (1), or blade-like (2).

152 (153). Stapes (curvature). Stapes with pronounced dorsodistal curvature (0), or abbreviated without such curvature, directed laterally towards vertically aligned otic notch (1).

153 (154). Ceratobranchials. Bony elements absent (0), present in adults (1).

154 (155). Basibranchial. Bony element absent (0), present in adults (1).

155 (156). Hypobranchial elements. Bony elements absent (0), present in adults (1).

156 (157). Branchial denticles. Conical and attached to small ossicles in groups of 2-10 (0), or free and with brush-like end (1).

\section{Axial skeleton}

157 (158). Presacral count. More than 28 (0), or 23-25 vertebrae (1), or less than 21 (2) (Character-states not ordered). (Witzmann and Schoch 2006).

158 (159). Caudal count. Similar to presacral count or higher (0), or much lower (1).

159 (160). Transverse process (orientation). Short, directed posteriorly $(0)$, or distally extended with diapophysis pointing laterally (1). 
160 (161). Transverse process (length). Shorter than dorsal spine is high (0), or markedly longer (1).

161 (162). Neural spine (height). As high as distance between zygapophyses (0), or higher (1). (Witzmann and Schoch 2006).

162 (163). Intercentrum (shape). Presacral intercentra form simple wedges (0); or dorsally closed discs (1); or dorsally closed and elongated cylinders (2). (Yates and Warren 2000).

163 (164). Intercentrum (width). Chordal canal wider than intercentrum high (0), narrower (1). (Witzmann and Schoch 2006).

164 (165). Intercentrum (ventral surface). Ventral surface shorter than wide in ventral view, giving transversely rectangular outline $(0)$, or as long as wide, quadrangular (1).

165 (166). Intercentrum anterior surface. Always concave (0), or convex at least in some presacral centra (1). (Warren and Snell 1991). 166 (167). Parapophysis. Segmental (0), or intersegmental (1). (Warren and Snell 1991).

167 (168). Pleurocentrum (presence). Ossified (0), unossified (1). (Witzmann and Schoch 2006).

168 (169). Pleurocentrum (lateral surface). As large as that of intercentrum (0), or smaller (1). (Witzmann and Schoch 2006).

169 (170). Pleurocentrum (ventral extension). Wedged between successive intercentra and not reaching ventral margin of intercentra (0), or pleurocentra ventrally expanded to near each other (1), or ventrally fused to form a single cylindral element (2). (Schoch and Rubidge 2005).

170 (171). Ribs (length). Moderately elongate thoracic ribs curved distoventrally (0), or such ribs foreshortened without distal curvature (1).

171 (172). Ribs (ventral extension). Rib heads (tuberculum and capitulum) confluent (0), or clearly set off and widely separated in mid-trunk region (1).

172 (173). Ribs (uncinate blades). If present, small and spine-like (0), or extensive and blade-like (1). (Witzmann and Schoch 2006). 173 (174). Ribs (uncinate spines). Short (0), or elongated, as long as shaft (1).

174 (175). Cleithrum. With broadened dorsal head region (0), or a simple rod (1).

175 (176). Cleithrum. Head with slightly convex or straight anterior rim (0), or with pronounced anterior projection (1). 176 (177). Cleithrum. Dorsal head region confined to anterior rim of scapula (0), or posteriorly extended to cover dorsal rim of scapula (1).

177 (178). Clavicle (ventral blade). Wide, triangular, overlapping interclavicle broadly (0), or slender, with minor overlap (1).

178 (179). Interclavicle (length). Shorter than posterior skull (0), or substantially longer (1).

179 (180). Interclavicle (ontogeny). Without major proportional change in ontogeny $(0)$, or decreasing proportionally relative to skull length (1).

180 (181). Interclavicle (central ornamented area). Rhomboidal (0), or pentagonal and posteriorly widest (1).

181 (182). Interclavicle (proportions). As long as wide (0), or 1.3 times as long as wide (1), or more than twice as long as wide (2). 182 (183). Interclavicle (posterior margin). With posterior process (0), or transversely straight (1).
183 (184). Interclavicle (anterior margin). Serrated (0), or smooth (1).

184 (185). Interclavicle (anterior stylus). Anterior portion of interclavicle variably shaped but not longer than posterior one, as measured by the centre of ornamentation (0), or substantially longer than posterior one (1).

185 (186). Interclavicle (posterior stylus). Posterior end rounded or blunt (0), or with elongated stylus or parasternal process (1).

186 (187). Interclavicle, clavicles. Clavicles broadly separated by interclavicle ventrally (0), or leaving only narrow stripe of interclavicle in between (1), or in contact and excluding anterior part of interclavicle from ventral exposure (2).

\section{Limb skeleton}

187 (188). Scapula (glenoid facet). Ossified (0), or unossified in adults (1). (Witzmann and Schoch 2006).

188 (189). Scapula (height). Maximally two times longer (higher) than wide (0), or dorsally extended and fully ossified, three times higher than wide (1). (Schoch and Rubidge 2005).

189 (190). Humerus (ontogeny). Short cylinder in larvae, elongates at slow rate (0), or with substantial shaft in larvae (1), or very long rod from small stages on (2). (Boy 1972).

190 (191). Humerus (adult shaft). No shaft proper, humerus blade-like in cross-section (0), or with short shaft oval in cross-section (1), or shaft elongate and slender, comprising more than $50 \%$ of the humerus with rounded cross-section (2).

191 (192). Humerus (entepicondylar foramen). Present (0), or absent (1).

192 (193). Humerus (supinator). Present (0), or absent (1). (Yates and Warren 2000).

193 (194). Humerus (condyles). Distal end at least partially ossified with identifiable condyles (0), or unfinished without condyles (1), or with fully established condyles (2). (Schoch and Rubidge 2005, modified).

194 (195). Humerus (torsion). Strong, 70-90 (0), or weak, well below $60^{\circ}$ (1) (Witzmann and Schoch 2006)

195 (196). Carpals. All unossified (0), or all at least some ossified (1). 196 (197). Manual digit count. Five (0), or four (1).

197 (198). Ilium (shaft). Shaft of variable length but laterally flattened (0), or very long and slender (1).

198 (199). Ilium (dorsal end). Tip of dorsal end continuous (0), or much broadened (1).

199 (200). Ilium (height). Shaft more than twice the length of the base (0), or shorter (1). (Schoch and Rubidge 2005)

200 (201). Ilium (orientation). Main axis of shaft inclined posterodorsally (0), or vertical (1).

201 (202). Ilium (tip). Dorsal end two-headed (0), or single-headed (1).

202 (203). Pubis. Ossified (0), or unossified (1).

203 (204). Femur. Intercondylar fossa forming deep and elongated trough (0), or reduced to short depression (1). (Yates and Warren 2000).

204 (205). Femur (trochanter). Internal trochanter present as discrete process (0), or reduced to a shallow crest (1), or greatly enlarged to form a massive projection (2). 
205 (206). Tarsals. At least some are ossified (0), or all unossified (1).

\section{Postcranium, general}

206 (207). Gastral squamation. Ossified ventral dermal scales (0), or scales absent (1). (Yates and Warren 2000).

207 (208). Squamation. Dermal scales oval to spindle-shaped (0), or broad-oval with "microsaur-type" ornament (1). (Boy 1972).

208 (209). Osteoderms. Absent (0), or present as single row (1), or more numerous to form a carapace (2).

209 (210). Osteoderms (articulations). Simple set of osteoderms arranged in one layer if present (0), or double set of two layers, the ventral one fused to the tip of the neural arch (1).

210 (211). Osteoderms (width). An intra-dissorophid character: Narrow median osteoderms (0), or transversely extended plates (1). 211 (212). Rib cage. Trunk narrower than skull or as wide (0), or trunk substantially wider than lateral margin of cheeks at about mid-level (1).

\section{New Characters}

212. Shape of centrale 4 of carpus. Lateral side facing ulna has single facet contacting only the intermedium (0), or two separate lateral facets one contacting intermedium and a second facing, but not contacting, the ulnare (1).

213. Proximal end of metacarpal 1 . Contacts only distal carpal 1 (0), or contacts distal carpal 1 and centrale 1.

214 . Shape of metacarpal 1 . Proximo-distally symmetrical with length greater than width (0), or proximo-distally asymmetrical with length and width approximately equal (1).

215. Relative lengths of mutual contact surfaces of tibiale and centrale 4. Equal (0), or unequal with length of contact surface on tibiale less than length of contact surface on centrale 4 (1).

216. Contact surfaces for tibia and fibula on intermedium of tarsus. Confluent (0), or separate (1).

217. Shape of fibulare. Latero-medial width greater than proximo-distal height (0), or latero-medial width less than proximo-distal height (1).

218. Centrale 2 of tarsus. Does not contact distal tarsal $1(0)$, contacts distal tarsal 1 (1).

219. Shape of centrale 4 of tarsus. Approximately diamond-shaped (0), or rectangular with medial height greater than lateral height (1).

220. Contact between centrale 4 and distal tarsal 4 . Absent (0), or present (1).

\section{APPENDIX 3}

\section{List of unambiguous characters for each clade in Figure 13.}

Character number and the description of the derived state are included for each node. An asterisk indicates a character with a ci $=1$ (i.e. no homoplasy).

\section{Node A: Temnospondyli}

33. Sensory sulci. Absent from the skull roof of adults (reversal). $72^{*}$. Postparietal-exoccipital. Pillar-like dorsal process of exoccipital firmly sutured to ventral side of postparietal and oblique process of exoccipital sutured with ventral ramus of tabular. $88^{*}$. Interpterygoid vacuities. Rounded, oval openings. $92^{*}$. Vomer. Large plate, widely separating choanae.

110. Parasphenoid plate (size). Basal plate at level posterior to basicranial joint as wide or wider than parietals.

$138^{*}$. Dentigerous palatal ossicles. Present within interpterygoid vacuities.

149. Stapes (quadrate process). Present.

$150^{*}$. Stapes (ventral process). Present, giving the proximal region two heads.

$151^{*}$. Stapes (shape). Rod-like element with elongated stylus.

157. Presacral count. 23-25 vertebrae.

190*. Humerus (adult shaft). Short shaft oval in cross-section. 196. Manual digit count. Four.

\section{Node B:}

10. Premaxilla (alary process). Present, forming a posterior hooklike indentation.

104. Basipterygoid ramus. Pterygoid with transversely extended process producing posteriorly wider vacuities.

\section{Node C: Rhachitomi}

59. Intertemporal. Absent.

109. Parasphenoid plate. Basal plate quadrangular to wider than long. 154. Basibranchial. Bony element present in adults.

191*. Humerus (entepicondylar foramen). Absent.

217. Shape of fibulare. Latero-medial width less than proximo-distal height.

\section{Node D:}

74. Quadrate and occipital condyles. Quadrate condyles at same level to occipital ones.

155. Hypobranchial elements. Bony elements present in adults.

187. Scapula (glenoid facet). Unossified in adults.

194. Humerus (torsion). Weak, well below $60^{\circ}$.

195. Carpals. All unossified (reversal).

202. Pubis. Unossified.

205. Tarsals. All unossified.

\section{Node E:}

45. Posterior skull table (length). Less than 0.6 times the width. 46*. Postorbital (shape). Short.

70. Posterior skull rim. Quadrate trochlea at one level or anterior to tabular horns.

$177^{*}$. Clavicle (ventral blade). Slender with minor overlap on interclavicle.

$189^{*}$. Humerus (ontogeny). Substantial shaft in larvae.

198. Ilium (dorsal end). Tip of dorsal end much broadened.

\section{Node F: Dissorophoidea}

19*. Naris (flange). Ventral (inner) side of prefrontal, lacrimal, and nasal bearing a complicated bar-like structure (narial flange) permitting contact with the antorbital bar.

26. Height of jugal below orbit relative to height of maxilla. Height of jugal less than or equal to height of maxilla.

30. Interorbital distance. Narrower than or equalling orbital width (reversal). 


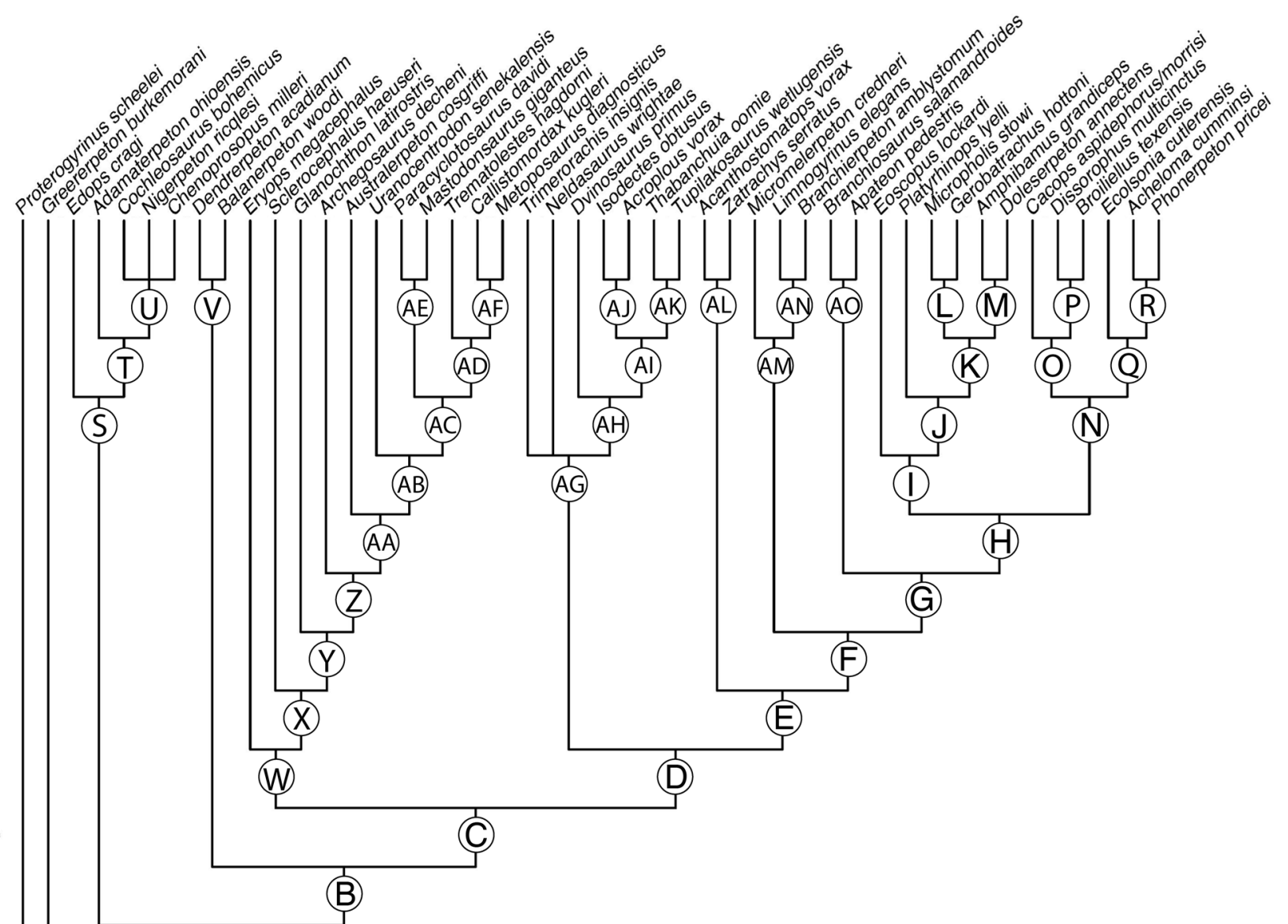

Figure 13. Strict consensus tree presented in Figure 11B with labeled nodes. Unambiguous characters diagnostic of each labeled node are listed in Appendix 3 .

39. Prefrontal (anterior end). Wide and blunt.

$42^{*}$. Prefrontal (process). Prefrontal underlying lacrimal laterally to reach the palatine.

55. Semilunar flange. Supratemporal forming marked ventral flange participating in medial bordering of otic notch.

58. Jugal-lacrimal. Separated by orbit or palate bones.

67*. Quadratojugal (medial process). Present.

101. Vomer-pterygoid. Separated by palatine.

126. Palatine (laterally exposed palatine, LEP). Present.

152. Stapes (curvature). Stapes abbreviated without such curvature, directed laterally towards vertically aligned otic notch.

169. Pleurocentrum (ventral extension). Pleurocentra ventrally expanded to near each other.

\section{Node G:}

157. Presacral count. Less than 21.

189*. Humerus (ontogeny). Very long rod from small stages on. $190^{*}$. Humerus (adult shaft). Shaft elongate and slender, comprising more than $50 \%$ of the humerus with rounded cross-section.

192. Humerus (supinator). Absent.

\section{Node H:}

74. Quadrate and occipital condyles. Quadrate condyles posterior to occipital ones (reversal).

195. Carpals. At least some ossified.

202. Pubis. Ossified (reversal).

205. Tarsals. At least some are ossified (reversal).

\section{Node I: Amphibamidae}

89. Interpterygoid vacuities, pterygoid. Vacuities laterally greatly extended at mid-level pushing pterygoid to the margin.

128*. Palatine, ectopterygoid (width). As narrow as maxilla.

\section{Node J:}

13. Premaxillary foramen. Premaxilla and nasal completely sutured (reversal).

70. Posterior skull rim. Quadrate trochlea posterior to tabular horns (reversal).

99*. Choana (medial). Anteromedially expanded giving choana a reniform outline.

114. Cultriform process (dentition). Main shaft with elongate tooth patch.

130. Ectopterygoid (length). Markedly shorter than palatine. 


\section{Node K:}

87. Ectopterygoid (fangs). Absent.

96. Vomerine pit and fontanelle. Pit present (posterior to mandible).

123. Pterygoid-palatine-ectopterygoid. Pterygoid only in contact with ectopterygoid.

\section{Node L: Micropholis and Gerobatrachus}

74. Quadrate and occipital condyles. Quadrate condyles at same level to occipital condyles.

158. Caudal count. Much lower than presacral count.

\section{Node M: Amphibamus and Doleserpeton}

52. Supratemporal. Quadrangular, giving a foreshortened posterior skull table.

$81^{*}$. Pedicely. At least some teeth with two separate mineralization centers (pedicellate).

169. Pleurocentrum (ventral extension). Ventrally fused to form a single cylindral element.

\section{Node N: Olsoniformes}

96. Vomerine pit and fontanelle. Pit present (posterior to mandible). 105. Basicranium (contact). Sutural contact between basal plate and pterygoid.

110. Parasphenoid plate (size). Basal plate at level posterior to basicranial joint substantially narrower than parietals (reversal). 152. Stapes (curvature). Stapes with pronounced dorsodistal curvature (reversal).

155. Hypobranchial elements. Bony elements absent (reversal).

169. Pleurocentrum (ventral extension). Wedged between successive intercentra and not reaching ventral margin of intercentra (reversal).

176*. Cleithrum. Dorsal head region posteriorly extended to cover dorsal rim of scapula.

188. Scapula (height). Dorsally extended and fully ossified, three times higher than wide.

199. Ilium (height). Shaft shorter than length of the base.

200. Ilium (orientation). Main axis of shaft vertical.

\section{Node O: Dissorophidae}

52. Supratemporal. Quadrangular, giving a foreshortened posterior skull table.

86. Parasphenoid (shagreen). Teeth entirely absent.

161. Neural spine (height). Higher than distance between zygapophyses.

209*. Osteoderms (articulations). Double set of two layers, the ventral one fused to the tip of the neural arch.

\section{Node P:}

210*. Osteoderms (width). An intra-dissorophid character: Transversely extended plates.

\section{Node Q: Trematopidae}

$18^{*}$. Naris (extension). Naris posteriorly expanded with distinct anterior and posterior regions giving external overall "key-hole" shape.

$77^{*}$. Dentition (upper jaw). Caniniform.

$97^{*}$. Vomerine septum. Present.

101. Vomer-pterygoid. Sutured (reversal).

192. Humerus (supinator). Present (reversal).

\section{Node R:}

131. Ectopterygoid (laterally exposed ectopterygoid, LEE). Present. Node S: Edopoidea

9. Preorbital region (length). More than twice the length of posterior skull table.

$11^{*}$. Premaxilla (prenarial portion). Very expanded, equaling the length of the frontal.

43. Prefrontal-jugal. In contact.

$47^{*}$. Postorbital (end). Posterior end with finger-like projection.

57. Jugal (anterior extension). Jugal extending anterior to anterior orbit margin.

95*. Vomerine ridges. Present, radiating from vomerine tusks anteriorly.

98. Choana (lateral). Anterolaterally expanded with triangular outline.

$102^{*}$. Vomer (anterior part). Anterior portion as long or longer than portion behind anterior level of choana.

105. Basicranium (contact). Sutural contact between basal plate and pterygoid.

\section{Node T:}

$7^{*}$. Ornament (preorbital). Zone of subdued ornament on the medial skull bones adjacent to the midline suture present.

Node U:

31. Frontal-nasal (length). Frontal shorter than nasal.

\section{Node V: Dendrerpetontidae}

26. Height of jugal below orbit relative to height of maxilla. Height of jugal less than or equal to height of maxilla.

170. Ribs (length). Thoracic ribs foreshortened without distal curvature.

192. Humerus (supinator). Absent.

\section{Node W: Eryopiformes}

12. Premaxilla (outline). Box-like and anteriorly blunt.

43. Prefrontal-jugal. In contact.

51*. Otic notch (position). Slit-like.

57. Jugal (anterior extension). Jugal extending anterior to level of anterior orbit margin.

93. Vomer (paired anterior depressions). Present.

108*. Basicranium (carotids). Internal carotids entered basicranium at posterolateral corner of bone.

161. Neural spine (height). Higher than distance between zygapophyses. 172. Ribs (uncinate blades). Extensive and blade-like.

204. Femur (trochanter). Internal trochanter greatly enlarged to form a massive projection.

\section{Node X: Stereospondylomorpha}

20. Nasal (lateral margin). Stepped, with lateral excursion anterior to lacrimal.

33. Sensory sulci. Extensive sensory sulci present on the skull of adults. 37. Maxilla (contact to nasal). Present.

66*. Tabular (ventral crest). Present and shallow.

129. Palatine, ectopterygoid (continuous tooth row). Present.

149. Stapes (quadrate process). Absent (reversal). 
178. Interclavicle (length). Substantially longer than posterior skull. 181*. Interclavicle (proportions). 1.3 times as long as wide. $215^{*}$. Relative lengths of mutual contact surfaces of tibiale and centrale 4. Unequal with length of contact surface on tibiale less than length of contact surface on centrale 4.

\section{Node Y:}

9. Preorbital region (length). More than twice the length of posterior skull table.

187. Scapula (glenoid facet). Unossified in adults.

202. Pubis. Unossified.

\section{Node Z:}

84. Transverse tooth row (transvomerine). Present and transverse. 194. Humerus (torsion). Weak, well below $60^{\circ}$.

\section{Node AA:}

20. Nasal (lateral margin). Straight (reversal).

56. Jugal (ventral process). Insula jugalis framing subtemporal window.

90. Anterior palatal opening(s). Perforated to accommodate symphyseal fangs.

91. Anterior palatal opening(s). Paired.

93. Vomer (paired anterior depressions). Absent (reversal).

\section{Node AB: Stereospondyli}

12. Premaxilla (outline). Parabolically rounded (reversal).

15. Snout (internarial distance). Narrower than interorbital distance (reversal).

27. Orbit margins. Flush with roof.

$51^{*}$. Otic notch (position). Small and rounded, confined to dorsomedial part of squamosal.

63*. Squamosal (falciform crest). Posterior rim of squamosal with convex projection, referred to as falciform crest.

78*. Dentition (marginal, tooth bases). Forming transversely broadened ovals.

105. Basicranium (contact). Sutural contact between basal plate and pterygoid.

159*. Transverse process (orientation). Distally extended with diapophysis pointing laterally.

161. Neural spine (height). As high as distance between zygapophyses (reversal).

$183^{*}$. Interclavicle (anterior margin). Smooth.

\section{Node AC:}

$34^{*}$. Infraorbital sulcus. With pronounced S-shaped lacrimal flexure. 61. Squamosal-tabular (dorsal). Sutured.

68. Quadratojugal-maxilla. Separated by jugal (reversal).

70. Posterior skull rim. Quadrate trochlea at one level or anterior to tabular horns.

74. Quadrate and occipital condyles. Quadrate condyles at same level as occipital ones.

76. Dentition (marginal). Homogeneous, small teeth, equidistant.

80. Dentition (vomer). Dentition entirely restricted to vomerine fangs.

87. Ectopterygoid (fangs). Absent.

101. Vomer-pterygoid. Separated by palatine.

$106^{*}$. Basicranium, suture. Suture almost as long as basal plate.
111. Cultriform process (width). Base merging continuously into plate.

117. Pterygoid, exoccipital. Sutured lateral to parasphenoid.

121. Pterygoid width. Palatine and quadrate regions forming broad shelves.

$125^{*}$. Palatine, vomer. Suture with medial wing framing the interpterygoid vacuity anteriorly.

139. Postglenoid area. Longer than glenoid facet.

$171^{*}$. Ribs (ventral extension). Rib heads (tuberculum and capitulum) clearly set off and widely separated in mid-trunk region. $184^{*}$. Interclavicle (anterior stylus). Anterior portion of interclavicle substantially longer than posterior one.

$186^{*}$. Interclavicle, clavicles. Clavicles leaving only narrow stripe of interclavicle in between.

205. Tarsals. All unossified.

\section{Node AD:}

$5 *$. Ornament (general). High ridges throughout.

$6^{*}$. Ornament (intensive growth). Prepineal growth zone estab-

lished on extended anterior parietal and postorbital.

$23^{*}$. Lacrimal (position). Confined to lateral orbit margin.

26. Height of jugal below orbit relative to height of maxilla.

Height of jugal less than or equal to height of maxilla.

43. Prefrontal-jugal. Separated by lacrimal (reversal).

$49 *$. Postorbital, postfrontal. Long or longer than supratemporal and parietal.

57. Jugal (anterior extension). Jugal ending at or behind level of anterior orbit margin (reversal).

79*. Palatal tusks (cross-section). Laterally compressed and keeled at least on one side.

123. Pterygoid-palatine-ectopterygoid. Pterygoid only in contact with ectopterygoid.

143*. Preglenoid process. Labial side of surangular forming dorsal projection well above the level of the glenoid articulation.

$163^{*}$. Intercentrum (width). Chordal canal narrower than intercentrum is high.

206. Gastral squamation. Scales absent.

\section{Node AE:}

$4^{*}$. Ornament (snout). Mostly radial, elongated grooves.

39. Prefrontal (anterior end). Wide and blunt.

86. Parasphenoid (shagreen). Teeth entirely absent.

94. Anterior palatal depression. Straight transverse.

$124^{*}$. Palatine, ectopterygoid. Palatine with posterolateral process excluding the ectopterygoid from interpterygoid vacuity and contacting pterygoid.

154. Basibranchial. Bony element absent (reversal).

160. Transverse process (length). Markedly longer than dorsal spine is high.

\section{Node AF:}

9. Preorbital region (length). Less than twice the length of posterior skull table (reversal).

$17^{*}$. Naris (position). Set well medially, opening anteriorly.

$71^{*}$. Occipital flange. Descending flange of occipital portion of postparietal ia long smooth blade as long as the dermal portion of the postparietal. 
122*. Pterygoid, ectopterygoid. Palatine ramus with posteromedial projection of ectopterygoid.

134*. Quadrate trochlea. Medial bulge at least two times longer and twice as wide than lateral one.

136*. Exoccipital condyles. Almost the complete element posterior to level of occipital flange.

162. Intercentrum (shape). Presacral intercentra form dorsally closed discs.

$164^{*}$. Intercentrum (ventral surface). Ventral surface as long as wide, quadrangular.

$165^{*}$. Intercentrum anterior surface. Convex at least in some presacral centra.

186*. Interclavicle, clavicles. Clavicles in contact and excluding anterior part of interclavicle from ventral exposure.

\section{Node AG: Dvinosauria}

33. Sensory sulci. Extensive sensory sulci present on the skull of adults. 80. Dentition (vomer). Dentition entirely restricted to vomerine fangs. 90. Anterior palatal opening(s). Vomer and premaxilla perforated to accommodate symphyseal fangs.

91. Anterior palatal opening(s). Paired.

104. Basipterygoid ramus. Pterygoid with short, posteromedially curved basipterygoid process, constricting palatal vacuities posterolaterally (reversal).

153. Ceratobranchials. Bony elements present in adults.

157. Presacral count. More than 28 (reversal).

178. Interclavicle (length). Substantially longer than posterior skull.

\section{Node AH:}

16*. Nasal (width). Nasal as wide as long.

68. Quadratojugal-maxilla. Separated by jugal (reversal).

74. Quadrate and occipital condyles. Quadrate condyles well anterior to occipital ones.

119. Pterygoid, squamosal. With open fissure.

139. Postglenoid area. Longer than glenoid facet.

203. Femur. Intercondylar fossa reduced to short depression.

\section{Node AI:}

64. Tabular (horn). Entirely absent.

86. Parasphenoid (shagreen). Teeth entirely absent.

101. Vomer-pterygoid. Separated by palatine.

155. Hypobranchial elements. Bony elements absent (reversal).

\section{Node AJ: Saurerpetontidae}

25 . Orbit and naris. Separated only by tiny quadrangular lacrimal.

33. Sensory sulci. Sensory sulci of adults restricted to circumorbital sulcus.

61. Squamosal-tabular (dorsal). Separated by supratemporal (reversal).

148. Mandibular osteoderms. Throat region covered with a mosaic of ventral osteoderms between mandible and dermal pectoral girdle.

\section{Node AK: Tupilakosauridae}

$21^{*}$. Lacrimal. Absence of lacrimal as separate ossification.

44. Prefrontal-maxilla. In contact.

117. Pterygoid, exoccipital. Sutured lateral to parasphenoid.
118*. Pterygoid, basioccipital. Sutured lateral to parasphenoid. 121. Pterygoid width. Palatine and quadrate regions forming broad shelves.

123. Pterygoid-palatine-ectopterygoid. Pterygoid only in contact with ectopterygoid.

162. Intercentrum (shape). Presacral intercentra form dorsally closed discs.

\section{Node AL: Zatracheidae}

8*. Spines. Present along lateral flank of quadratojugal.

9. Preorbital region (length). More than twice the length of posterior skull table.

$14^{*}$. Premaxillary fontanelle. Encircling large fenestra extending posteriorly between the nasals.

31. Frontal-nasal (length). Frontal shorter than nasal.

38. Prefrontal-frontal. Prefrontal ending at one level with frontal. 52. Supratemporal. Quadrangular, giving a foreshortened posterior skull table.

96. Vomerine pit and fontanelle. Fenestra within pit.

105. (106). Basicranium (contact). Sutural contact between basal plate and pterygoid.

114. Cultriform process (dentition). Main shaft with elongate tooth patch.

154. Basibranchial. Bony element absent (reversal).

\section{Node AM: Micromelerpetontidae}

33. Sensory sulci. Extensive sensory sulci present on the skull of adults 83. Labyrinthodonty. Teeth never labyrinthodont.

157. Presacral count. More than 28 (reversal).

207*. Squamation. Dermal scales broad-oval with "microsaur-type" ornament.

\section{Node AN:}

80. Dentition (vomer). Dentition entirely restricted to vomerine fangs. Node AO: Branchiosauridae

38. Prefrontal-frontal. Prefrontal ending at one level with frontal. 52. Supratemporal. Quadrangular, giving a foreshortened posterior skull table.

80. Dentition (vomer). Dentition entirely restricted to vomerine fangs. 86. Parasphenoid (shagreen). Teeth entirely absent.

130. Ectopterygoid (length). Markedly shorter than palatine.

132*. Ectopterygoid (Y-shaped). Ectopterygoid Y-shaped, with posterior half separated from maxilla by a gap.

146. Posterior coronoid teeth. Absent.

147. Anterior, middle coronoid teeth. Absent.

\section{References for Appendices}

Anderson, J. S. 2005. On the skull of Cacops aspidephorus Williston (Tetrapoda; Temnospondyli; Dissorophidae) from the lower Permian of Texas. Part 1: Lower jaw anatomy. Pp. 15 in S. G. Lucas, and K. E. Zeigler (eds). The Nonmarine Permian, New Mexico Museum of Natural History and Science Bulletin 30. Albuquerque: New Mexico Museum of Natural History and Science. 
Anderson, J. S., A. C. Henrici, S. S. Sumida, T. Martens, and D. S. Berman. 2008. Georgenthalia clavinasica, a new genus and species of dissorophoid temnospondyl from the early Permian of Germany, and the relationships of the family Amphibamidae. Journal of Vertebrate Paleontology 28:61-75.

Berman, D. S., R. R. Reisz, and D. A. Eberth. 1985. Ecolsonia cutlerensis, an early Permian dissorophid amphibian from the Cutler Formation of north-central New Mexico. New Mexico Bureau of Mines and Mineral Resources Circular 191:1-31.

Boy, J. A. 1972. Die Branchiosaurier (Amphibia) des saarpfälzischen Rotliegenden (Perm; SW Deutschland). Abhandlungen des Hessischen Landesamt für Bodenforschung 65:5-137.

Boy, J. 1989. Über einige Vertreter der Eryopoidea (Amphibia: Temnospondyli) aus dem europäischen Rotliegend (?höchstes Oberkarbon - Perm) 2. Acanthostomatops. Paläontologische Zeitschrift 63:133-151.

Bystrow, A. P. 1938. Dvinosaurus als neotenische Form der Stegocephalen. Acta Zoologica 19:209-295.

Case, E. C. 1935. Description of a collection of associated skeletons of Trimerorhachis. Contributions from the Museum of Paleontology, University of Michigan 4:227-274.

Chase, J. 1965. Neldasaurus wrightae, a new rhachitomous labyrinthodont from the Texas Permian. Bulletin of the Museum of Comparative Zoology 133:153-225.

Damiani, R. J. 2001. A systematic revision and phylogenetic analysis of Triassic mastodonsauroids (Temnospondyli: Stereospondyli). Zoological Journal of the Linnaean Society 133:379-482.

DeMar, R. 1968. The Permian labyrinthodont amphibian Dissorophus multicinctus, and the adaptations and phylogeny of the family Dissorophidae. Journal of Paleontology 42:1210-1242.

Dilkes, D. W. 1990. A new trematopsid amphibian (Temnospondyli: Dissorophoidea) from the lower Permian of Texas. Journal of Vertebrate Paleontology 10:222-243.

Dilkes, D. W., and R. R. Reisz. 1987. Trematops milleri Williston, 1909 identified as a junior synonym of Acheloma cumminsi Cope, 1882, with a revision of the genus. American Museum Novitates 2902:1-12.

Englehorn, J., B. J. Small, and A. Huttenlocker. 2008. A redescription of Acroplous vorax (Temnospondyli: Dvinosauria) based on new specimens from the early Permian of Nebraska and Kansas, U.S.A. Journal of Vertebrate Paleontology 28:291-305.

Foreman, B. C. 1990. A revision of the cranial morphology of the lower Permian temnospondyl amphibian Acroplous vorax Hotton. Journal of Vertebrate Paleontology 10:390-397.

Fröbisch, N. B., and R. R. Reisz. 2008. A new lower Permian amphibamid (Dissorophoidea, Temnospondyli) from the fissure fill deposits near Richards Spur, Oklahoma. Journal of Vertebrate Paleontology 28:1015-1030.

Godfrey, S. J. 1989. The postcranial skeletal anatomy of the Carboniferous tetrapod Greererpeton burkemorani Romer, 1969. Philosophical Transactions of the Royal Society of London. Series B, Biological Sciences 323:75-133.
Holmes, R. 1980. Proterogyrinus scheelei and the early evolution of the labyrinthodont pectoral limb. Pp. 351-376 in A. L. Panchen (ed). The Terrestrial Environment and the Origin of Land Vertebrates. New York: Academic Press.

Jupp, R., and A. A. Warren. 1986. The mandibles of the Triassic temnospondyl amphibians. Alcheringa: An Australasian Journal of Palaeontology 10:99 - 124.

Laurin, M., and R. Soler-Gijón. 2006. The oldest known stegocephalian (Sarcopterygii: Temnospondyli) from Spain. Journal of Vertebrate Paleontology 26:284-299.

Milner, A. R. 1993. The Paleozoic relatives of lissamphibians. Herpetological Monographs 7:8-27.

Polley, B. P., and R. R. Reisz. 2011. A new lower Permian trematopid (Temnospondyli: Dissorophoidea) from Richards Spur, Oklahoma. Zoological Journal of the Linnean Society 161:789-815.

Ruta, M., and J. R. Bolt. 2006. A reassessment of the temnospondyl amphibian Perryella olsoni from the lower Permian of Oklahoma. Transactions of the Royal Society of Edinburgh: Earth Sciences 97:113-165.

Schoch, R. R. 2013. The evolution of major temnospondyl clades: an inclusive phylogenetic analysis. Journal of Systematic Palaeontology 11:673-705.

Schoch, R. R., and A. R. Milner. 2000. Stereospondyli. 1-203 pp. Verlag Dr. Friedrich Pfeil, München.

Schoch, R. R., and B. S. Rubidge. 2005. The amphibamid Micropholis from the Lystrosaurus Assemblage Zone of South Africa. Journal of Vertebrate Paleontology 25:502-522.

Schoch, R. R., and F. Witzmann. 2009. Osteology and relationships of the temnospondyl genus Sclerocephalus. Zoological Journal of the Linnean Society 157:135-168.

Sequeira, S. K. 1998. The cranial morphology and taxonomy of the saurerpetontid Isodectes obtusus comb. nov. (Amphibia: Temnospondyli) from the lower Permian of Texas. Zoological Journal of the Linnean Society 122.

Sequeira, S. E. K. 2003. The skull of Cochleosaurus bohemicus Frič, a temnospondyl from the Czech Republic (Upper Carboniferous) and cochleosaurid relationships. Transactions of the Royal Society of Edinburgh: Earth Sciences 94:21-43.

Shishkin, M. A. 1968. On the cranial arterial system of labyrinthodonts. Acta Zoologica 69:1-22.

Shishkin, M. A. 1973. The morphology of the early Amphibia and some problems of the lower tetrapod evolution. Trudy Paleontologicheskii Institut, Akademii Nauk SSSR:1-260.

Sigurdsen, T., and J. R. Bolt. 2010. The lower Permian amphibamid Doleserpeton (Temnospondyli: Dissorophoidea), the interrelationships of amphibamids, and the origin of modern amphibians. Journal of Vertebrate Paleontology 30:1360 - 1377.

Steyer, J. S., R. Damiani, C. A. Sidor, F. R. O'Keefe, H. C. E. Larsson, A. Maga, and O. Ide. 2006. The vertebrate fauna of the upper Permian of Niger. IV. Nigerpeton ricqlesi (Temnospondyli: Cochleosauridae), and the edopoid colonization of Gondwana. Journal of Vertebrate Paleontology 26:18-28. 
Warren, A. 1999. Karoo tupliakosaurid: a relict from Gondwana. Transactions of the Royal Society of Edinburgh: Earth Sciences 89:145-160.

Warren, A., and T. Black. 1985. A new rhytidosteid (Amphibia, Labyrinthodontia) from the Early Triassic Arcadia Formation of Queensland, Australia, and the relationships of Triassic temnospondyls. Journal of Vertebrate Paleontology 5:303-327.

Warren, A. A., and M. N. Hutchinson. 1983. The last labyrinthodont? A new brachyopid (Amphibia, Temnospondyli) from the Early Jurassic Evergreen Formation of Queensland, Australia. Philosophical Transactions of the Royal Society of London. Series B, Biological Sciences 303:1-62.

Warren, A., and N. Snell. 1991. The postcranial skeleton of Mesozoic temnospondyl amphibians: a review. Alcheringa 15:43-64.

Witzmann, F. 2006. Developmental patterns and ossification sequence in the Permo-Carboniferous temnospondyl Archegosaurus decheni (Saar-Nahe Basin, Germany). Journal of Vertebrate Paleontology 26:7-17.

Witzmann, F., and R. R. Schoch. 2006. The postcranium of Archegosaurus decheni, and a phylogenetic analysis of temnospondyl postcrania. Palaeontology 49:1211-1235.

Yates, A. M., and A. A. Warren. 2000. The phylogeny of the 'higher' temnospondyls (Vertebrate: Choanata) and its implications for the monophyly and origins of the Stereospondyli. Zoological Journal of the Linnaean Society 128:77-121. 